\title{
PATHOLOGICAL AND IMMUNOHISTOCHEMICAL STUDY OF P. MULTOCIDA CAPSULAR TYPE A IN TISSUES OF CHICKENS AND DUCKS INFECTED WITH FOWL CHOLERA
}

\author{
SAMAR GHALY ${ }^{1}$, WALAA AWADIN ${ }^{2}$ and AHMED ELSAWAK ${ }^{3}$ \\ ${ }^{1}$ Department of Pathology, Animal Health Research Institute, Mansoura, \\ ${ }^{2}$ Department of Pathology, Faculty of Veterinary Medicine, Mansoura University Postal box: 35516, \\ ${ }^{3}$ Department of Pathology, Faculty of Veterinary Medicine, Kafr El- Sheikh University Egypt
}

Received: 9 January 2017; $\quad$ Accepted: 27 February 2017

\begin{abstract}
Sixteen chickens' flocks and six ducks' flocks were surveyed for presence of fowl cholera (FC) during the period from July 2013 to November 2016. A total of 81 freshly dead birds (51 chickens of average age 50 to 180 days and 30 ducks of average age 30-100 days) were received from different farms and house breeding in Dakahlia Governorate at Mansoura Laboratory of Animal Health Research Institute for further laboratory examination. FC was diagnosed based on case history, postmortem lesions, bacteriological isolation, polymerase chain reaction (PCR), capsular typing, virulence factor detection (Tox A gene), and immunohistochemistry (IHC). In this study, Pasteurella multocida ( $P$. multocida) were bacteriologically isolated from 22 chickens and 16 ducks. The infection occurred in 4 layer chickens flocks, 2 breeder flocks and 3 broiler flocks. Meanwhile, all affected flocks of ducks were broiler. Age susceptibility in chickens varied as the age ranged from 30-54 days in broiler flocks, 45-150 days in layer flocks during the rearing period and before start egg production, 70-150 days in breeder flocks during the rearing period. In ducks the susceptible age ranged from 30-100 days. The most affected cases of chickens were from farm housing and the most affected cases of ducks were from back yard housing. Mortality rate in chickens was 0.03 to 0.36 and in ducks was 33.3 to $46.6 \%$. Main gross findings in affected chickens and ducks were corn meal liver, fibrinous perihepatitis and fibrinous pericarditis. Swollen hock joint and thickened foot pad were grossly detected in ducks only. The histopathological lesions in the infected ducks were more severe than those detected in the infected chickens that characterized by multiple granulomata in most examined organs. Therefore, the IHC positive reaction against antigen of $P$. multocida serotype A were more intensely stained and widely distributed in all examined organs of infected ducks than in chickens.
\end{abstract}

Key words: Pasteurella multocida, Histopathology, Immunohistochemistry, Ducks, Chickens, Fowl Cholera

\section{INTRODUCTION}

Fowl cholera (FC) is one of the most important highly contagious bacterial diseases caused by Pasturella multocida (P. multocida). FC causes high economic losses in poultry production. It produced $1.8-21 \%$ mortalities and $15-20 \%$ decreases in egg production, in addition to the costs of vaccination and treatment of diseased birds and finally culling of the infected flock (Kapetanov et al., 2000; Charitha Devi et al., 2012 and Wilkie et al., 2012). FC is more prevalent in late summer, fall and winter. The disease seasonality is considered one of the circumstances rather than low resistance. Chickens became more susceptible when they reached maturity age (Glisson

Corresponding author: Dr. WALAA AWADIN E-mail address: walaafekriawadin@yahoo.com Present address: Department of Pathology, Animal Health Research Institute, Mansoura. et al., 2008). There were many predisposing factors caused stress on birds increasing the risk of the disease despite of vaccination (Jonas et al., 2001). Improper environmental factors like cold temperature increased host susceptibility to avian cholera (Samuel et al., 2007). High environmental temperature, poor management (bad ventilation, dirty litter) and malnutrition (improper feeding) were found to help the development of the disease in turkeys (Simensen and Olson, 2001). Overcrowding of susceptible birds also was considered as one of the most important stress factors that enable the disease to affect large number of birds of different species (Blanchong et al., 2006). The disease was rarely reported in extensive production systems, including scavenging family chicken and duck production in developing countries (Mbuthia et al., 2008). Outbreaks were also associated with arrival of specific migratory species, such as Snow Geese (Blanchong et al., 2006). The virulence of the microorganism was greatly variable between different $P$. multocida strains (Wilkie et al., 2000; Petersen et al., 2001 and Samuel et al., 2003). 
P. multocida is a heterogeneous microorganism as the pathogenicity of each strain was greatly variable. Host susceptibility to these strains differed greatly among different bird species (Christensen and Bisgaard, 2000). Mortality affected many species of birds. P. multocida had a worldwide distribution and caused septicemic and respiratory disease in most of domestic and wild birds (Samuel et al., 2007). In Egypt, $P$. multocida is considered a common problem in duck farms resulting in significant economic losses. Recently, P. multocida was isolated from $60 \%$ of the examined ducks at Sharkia Governorate suffering from respiratory manifestations, lameness, corneal turbidity and diarrhea. $69.8 \%$ of the isolated P. multocida strains were capsular type A, $20.9 \%$ were of capsular type D and $9.3 \%$ were untypable (Saad Eldin and Reda, 2016). Similar percentages were also reported in Iran and Japan by Takahashi et al. (1996) and Khamesipour et al. (2014), respectively. Moreover, $P$. multocida showed the highest incidence in lungs and air sacs followed by liver, heart and spleen (Saad Eldin and Reda, 2016). Isolates of $P$. multocida harbored virulence associated genes resulting in marked resistance to some of the used antibiotics. The aim of this study was to isolate the cause of naturally occurring FC in chickens and ducks using bacterial culture, biochemical identification of the bacteria, polymerase chain reaction $(\mathrm{PCR})$, making capsular typing and virulence factor detection (Tox A gene). Furthermore, gross lesions, histopathological lesions and IHC staining of $P$. multocida capsular type A were differentiated in both chicken and ducks.

\section{MATERIALS AND METHODS}

\section{Birds:}

Sixteen chickens' flocks and six duck flocks were surveyed for presence of fowl cholera (FC) during the period from July 2013 to December 2016. A total of 81 freshly dead birds (51 chickens of average age 50 to 180 days and 30 ducks of average age 30-100 days) were received from different farms and house breeding in Dakahlia Governorate at Mansoura Laboratory of Animal Health Research Institute for further laboratory examination.

\section{Samples:}

After external and internal examination, tissue specimens were collected for histopathology and immunohistochemistry from both chickens and ducks then placed in $10 \%$ neutral buffered formalin. Tissue specimens collected from affected chickens and ducks were trachea, lungs, liver, kidney, heart, spleen, proventriculus, gizzard and small intestine. In ducks additional tissue samples were taken from swollen hock joint, brain in case of torticollis prior to death and skin in case of thickened foot pad. Other samples were taken from liver for bacteriological isolation.

\section{Bacterial isolation:}

Firstly, enrichment of bacteria was done by inoculated swabs from different organs onto buffered peptone water which incubated at $37^{\circ} \mathrm{C}$ for 24 hours under aerobic condition. Subculturing was done on 10 $\%$ defibrinated sheep blood agar plates which incubated at $37^{\circ} \mathrm{C}$ for 24 hours and checked for suspected colonies (non- hemolytic, grayish whitish dew drop like, small colonies with mousey odor). Suspected colonies were then picked up on semisolid nutrient agar for biochemical identification using some biochemical tests (catalase, oxidase, indol production, growth on MacConkey agar) according to Brooks et al. (2002); Deena and Adriana, (2005); Naowarat, (2007). Each isolate was preserved in freezer in buffered peptone water with $10 \%$ sterile glycerol according to Ozbey and Muz, (2006) when further analysis was needed.

\section{Polymerase chain reaction (PCR) and agar gel electrophoresis:}

The primers used for the detection of P. multocida were listed in (Table 1) (OIE, 2008). All the PCR reactions were carried out in a final $25 \mu \mathrm{L}$ reaction volume using 2xPCR Master Mix (Emerald Amp GT PCR Master Mix (Takara) Code No. RR310A). 12.5 $\mu \mathrm{L}$, DNA template $6 \mu \mathrm{L}, 20$ pmol of primer $1 \mu \mathrm{L}$ each, and PCR grade water $4.5 \mu \mathrm{L}$. Cycling profiles used for the $P$. multocida specific PCR consisted of primary denaturation at $94^{\circ} \mathrm{C}$ for 5 minutes, followed by second denaturation at $94^{\circ} \mathrm{C}$ for 30 seconds, annealing at $55^{\circ} \mathrm{C}$ for 1 minute, extension at $72^{\circ} \mathrm{C}$ for 1 minute and a final extension at $72^{\circ} \mathrm{C}$ for 10 minutes. Similarly, $P$. multocida serotype A specific PCR consisted of primary denaturation at $94^{\circ} \mathrm{C}$ for 5 minutes, followed by second denaturation at $94^{\circ} \mathrm{C}$ for 30 seconds, annealing at $55^{\circ} \mathrm{C}$ for 1 minute, extension at $72^{\circ} \mathrm{C}$ for 1 minute and a final extension at $72^{\circ} \mathrm{C}$ for 10 minutes. DNA sample from $P$. multocida serotype $\mathrm{B}$ was used as negative control. Electrophoresis of the PCR products was done using $2.0 \%(\mathrm{w} / \mathrm{v})$ agarose gel. After electrophoresis, the DNA was stained for 10 minutes in Ethidium bromide (at $0.5 \mu \mathrm{g} / \mathrm{mL}$ ) and visualized using ultraviolet cabinet. The gel was photographed by a gel documentation system and the data was analyzed through computer software.

\section{Histopathological Examination:}

All specimens were fixed in $10 \%$ neutral buffered formalin for histopathological examination. After fixation, all specimens were dehydrated in graded alcohol, embedded in paraffin. Five microns sections were obtained and stained with routine hematoxylin and eosin stain (H\&E) as described by Bancroft and Stevens (1990).

\section{Immunohistochemistery (IHC):}

The laboratory methods were carried out at Pathology Department, Faculty of Medicine, Mansoura University. Paraffin sections from all organs were cut 
at 5 microns thickness and placed on positively charged slides (coated slides), deparafinized and dehydrated. After rinsing in phosphate buffered saline (PBS), 3\% hydrogen peroxide was applied for 5 minutes to block the endogenous peroxidase. Antigen retrieving was applied to sections using wet method by keeping slides in a wet chamber for 2 hours. The sections were immunostained using rabbit monoclonal anti- $P$. multocida capsular type A antibody with dilution of 1:4000 in PBS. After washing with $\mathrm{PBS}$, slides were incubated at $37^{\circ} \mathrm{C}$ for 45 minutes with Envision and anti-rabbit -horse radish peroxidase labeled polymer kit, DAKO (Carpenteria, CA). The IHC reaction was developed using 3, 3-diaminobenzidine DAB (from DAKO Carpenteria, CA) for 5-10 minutes. Sections were counterstained with Mayer's hematoxylin. Test slides incubated with PBS were used as negative control sections. Intensity of IHC staining against $P$. multocida were scored $(0-+3) ; 0$ negative, +1 weak staining in $\leq 10 \%$ of section, +2 moderate staining in $10-30 \%$ of section and +3 strong staining in $\geq 30 \%$ of section.

\section{RESULTS}

\section{Susceptibility of chickens and ducks to FC}

The positive FC cases were collected from 9 chicken flocks out of 16 and from only 3 duck flocks out of 6 (Table 2). The disease occurred nearly all over the year with an increase in the rate of infection during seasonal weather changes as in March, May, July and in winter season in November and December. The most affected cases of chickens were from farm housing and the most affected cases of ducks were from back yard housing. In the present study, the infection occurred in 4 layer chickens flocks, 2 breeder flocks and 3 broiler flocks. Meanwhile, all affected flocks of ducks were broiler. Age susceptibility in chickens varied as the age ranged from 30-54 days in broiler flocks, 45-150 days in layer flocks during the rearing period and before start egg production, 70-150 days in breeder flocks during the rearing period. In ducks the susceptible age ranged from 30-100 days. Mortality rate per week was generally low in both chickens and ducks farms compared to total number of bird per flock. Mortality rate in chickens was 0.03 to 0.36 and in ducks was 0.8 to $46.6 \%$ (Table 2 ).

\section{Isolation and biochemical identification of the $P$. multocida:}

All the isolates were examined for their cultural, morphological and biochemical characteristics. Thirty eight isolates ( 22 for chickens $43 \%$ and 16 for ducks $53 \%$ ) out of the eighty one isolates (51 for chickens and 30 for ducks) were positive based on colony characteristics of $P$. multocida on blood agar. The growth appeared as small grayish white dew drop like colonies without hemolysis and associated with mousey odor. None of these isolates was able to grow on MacConkey agar. The results of biochemical tests were positive for each of the following catalase, oxidase, indol production. The positive cases were collected from 9 chicken flocks and 3 duck flocks.

\section{Polymerase chain reaction (PCR), capsular typing and virulence factor detection:}

Two PCR- positively $P$. multocida isolates (1chicken and 1duck) out of five ( 2 chicken and 3 duck) were identified by the presence of Kmtl gene (that detected the presence or absence of $P$. multocida) at amplicon size of $460 \mathrm{bp}$. Tox $A$ gene that indicated for virulence of $P$. multocida strains was detected in both chicken and duck isolates at amplicon size of $864 \mathrm{bp}$. The M-PCR (multiplex PCR) showed that both chicken and duck $P$. multocida strains were belonging to capsular type A at amplicon size of 1044 bp (Fig. 1A-F).

\section{Gross pathology in chickens:}

Grossly all examined chickens showed congested and cyanotic skin under the feather. Feathers around vent were soiled with greenish diarrhea and edema in face. Congestion of the breast muscle was seen after removal of the skin. The air sacs were somewhat cloudy and the lungs were congested. Corn meal liver characterized by enlarged, severely congested liver with friable texture and pointed edges. Numerous pin point grayish white foci were seen on liver surface with torn capsule. Fibrinous perihepatitis was also seen. Fibrinous peritonitis was seen which led to adhesion of different parts of intestine with presence of fibrin deposits in the abdomen. Spleen was enlarged and congestion. Heart showed congested coronary blood vessels, petechial hemorrhage on coronary fat and fibrinous pericarditis. Kidneys were congested. Small intestine showed congested serosal blood vessels (Fig. 2A-F).

\section{Gross pathology in Ducks:}

Grossly, the examined ducks showed greenish diarrhea soiled the vent and general congestion of the body after removal of the skin. Congestion of trachea and lungs were found in all examined cases. Corn meal liver characterized by enlarged, severely congested liver with friable texture and few pin points grayish white foci were seen on surface. Fibrinous perihepatitis was also obvious. The air sacs and peritoneum were somewhat cloudy and opaque. Heart showed fibrinous pericarditis and congested coronary blood vessels. Kidneys were congested in most cases and pale in few cases. Spleen was enlarged. The brain did not show any gross lesions. Hock joint was swollen (Fig. 2H-I). On opening the affected joint, yellowish fibrinopurulent exudate was seen filled joint cavity and attached to ulcerated cartilaginous epiphyseal surface. Skin of foot pad was thickened. 


\section{Histopathology and IHC in chickens infected with FC: \\ Trachea:}

Trachea of chickens showed focal loss of epithelial lining by H\&E. By IHC trachea showed negative staining (score 0 ) for P. multocida capsular type A antigen (Fig. 3A).

\section{Lungs:}

Lungs of chickens showed extensive widening of interstitial tissue due to congestion, edema and leukocytic cells infiltration. Air alveoli showed presence of pale eosinophilic edematous fluid inside their lumena with presence of perivascular edema. Fibrinous exudate infiltrated with leukocytes with presence of basophilic bacterial colonies was seen inside parabronchial lumen. Deposition of fibrinous exudate was also observed in parabronchial walls. Focal necrotic area and granuloma formation surrounded by leukocytes were seen replacing pulmonary parenchyma in some cases. Closure of the openings of air capillaries inside the lumen of parabronchi was noticed due to accumulation of exudates, leukocytes and basophilic bacterial colonies. Perivascular leukocytic cells infiltration mainly heterophils and macrophages was observed. By IHC, the lung of chickens showed moderate positive brown immunolabelling $($ score +2$)$ for $P$. multocida capsular type A antigen in interstitial tissue and inside blood in blood vessels and in inter alveolar capillaries (Fig. 3B-D).

\section{Liver:}

Liver of chickens demonstrated extensive thickening of hepatic capsule with fibrinous exudate forming psudomembrane. Multifocal areas of coagulative necrosis with heterophils infiltration were noticed along with perivascular mononuclear cells (MNCs) infiltration was seen. In other cases, multifocal areas of coagulative necrosis with fibrosis were present. Nuclei of necrotic hepatocytes were pyknotic and karyorrhectic and hepatic blood vessels were congested. Besides areas of necrosis, the hepatocytes showed vacuolar degeneration. Angiopathy was seen in walls of hepatic blood vessels that filled with hemolyzed blood. Inside hemolyzed blood, capsulated bipolar coccobacilli could be seen. The bile ducts showed dilation and desquamation of biliary epithelial cells in their lumen. Basophilic bacterial colonies were noticed inside their lumena. MNCs were seen surrounded necrotic hepatocytes and as focal aggregation in liver parenchyma with focal perivascular fibrosis in the portal area. By IHC, liver of chicken showed strong positive brown immunolabelling (score +3 ) for $P$. multocida capsular type A antigen was seen inside the hepatocytes mainly around hepatic blood vessels and inside blood (Fig. 4A\&B).

\section{Kidneys:}

Kidneys of chickens showed congested renal blood vessels, edema and mild to severe interstitial hemorrhage. Renal tubules showed focal to diffuse coagulative necrosis which infiltrated with heterophils. By IHC, kidneys of chickens showed weak positive brown immunolabelling $($ score +1$)$ for $P$. multocida capsular type A antigen inside blood and renal tubules (Fig. 4C\&D).

\section{Heart:}

Heart of chickens demonstrated fibrinous and fibrinopurulent pericarditis which characterized by deposition of pale eosinophilic fibrin threads, congested capillaries, edema, heterophils and macrophages infiltration. Myocarditis was seen in some sections characterized by heterophils infiltration among cardiac muscle fibers. In addition, severe vacuolation, shrinkage and fibrosis of cardiac muscle fibers were obvious. Markedly congested blood vessels were also noticed among hyalinized cardiac muscle fibers. By IHC heart showed negative staining (score 0) for P. multocida capsular type A antigen (Fig. 5A).

\section{Spleen:}

Spleen of chickens showed eosinophilic fibrin deposition in red pulp, perivascular fibrosis with aggregation of heterophiles and bacterial coccobacilli were found around central arterioles. Sinus catarrh characterized by distension of splenic sinusoids with leukocytes. Accumulation of pale eosinophilic edema was observed in some cases. The splenic white pulp revealed moderate to severe depletion of lymphocytes from lymphoid follicles which replaced by heterophils. By IHC Spleen of chickens showed weak positive brown immunolabelling $($ score +1$)$ for $P$. multocida capsular type A antigen inside red pulp (Fig. 5B-D).

\section{Proventriculus:}

Proventriculus of chickens showed necrosis and sloughing of surface epithelium with denuded lamina propria. Desquamation of glandular epithelium inside lumen of gastric glands was also seen. By IHC, proventriculus showed negative staining (score 0 ) for P. multocida capsular type A antigen (Fig. A).

\section{Gizzard:}

Gizzard of chickens showed necrosis of surface epithelium with atrophied gastric glands in lamina propria. By IHC, gizzard showed negative staining (score 0 ) for $P$. multocida capsular type A antigen (Fig. 6B).

\section{Small intestine:}

Small intestine of chickens showed desquamation of epithelial cells covering villi and in severe cases atrophy, fusion or sloughing of villi along with congested serosal blood vessels were seen. 
Eosinophilic fibrin deposition was seen on serosal covering. By IHC, small intestine showed negative staining (score 0) for P. multocida capsular type A antigen (Fig. 6C\&D).

\section{Histopathology and IHC in ducks infected with FC: \\ Trachea:}

Trachea of duck showed necrosis and sloughing of epithelial lining with focal leukocytic cells infiltration in lamina propria. Multiple granulomata were detected in the tracheal wall characterized by necrosis in the center surrounded by lymphocytes, macrophages and Langhan's giant cells. Dilated lymphatics were seen around granulomata. By IHC, weak positive brown immunolabelling for $P$. multocida capsular type A antigen was seen in the lining necrotic epithelium of the lumen and strong positive brown immunolabelling $($ score +3$)$ for $P$. multocida capsular type A antigen in tracheal wall particularly in the muscular layer (Fig. 7A-D).

\section{Lung:}

Lungs of duck showed fibrinopurulent pleuropneumonia, fibrinous exudate, leukocytic cells infiltration besides basophilic bacterial colonies replaced pulmonary parenchyma. Diffuse congestion in blood capillaries and accumulation of fibrinous exudate in wall of the parabronchus led to occlusion of openings of air capillaries. Focal areas of necrosis and fibrosis were additionally seen in pulmonary parenchyma. Basophilic bacterial colonies could be seen inside lesion. Focal granuloma was observed in pulmonary parenchyma with presence of foci of calcification and multinucleated giant cells. By IHC, strong positive brown immunolabelling $($ score +3$)$ for $P$. multocida capsular type A antigen was observed in pulmonary parenchyma of duck, in the alveoli and inside blood in pulmonary blood vessels (Fig. 7E\&F).

\section{Liver:}

Liver of duck showed granuloma formation which characterized by focal area of necrosis surrounded by leukocytic cells infiltration and Langhan's giant cells. Coagulative necrosis in hepatocytes with dilated sinusoids and hypertrophied von Kupffer cells. Focal fibrosis was demonstrated which infiltrated with MNCs. By IHC, the liver showed moderate positive brown immunolabelling $($ score +2$)$ for $P$. multocida capsular type A antigen inside affected hepatic parenchyma (Fig. 8A\&B).

\section{Kidneys:}

Kidneys of duck showed diffuse coagulative necrosis involving renal tubules and glomerulus with leukocytic cells infiltration were seen, basophilic bacterial colonies were observed perivascular and inside renal glomerulus. By IHC, kidney of duck showed strong positive brown immunolabelling (score +3 ) for $P$. multocida capsular type A antigen inside renal parenchyma (Fig. 8C\&D).

\section{Heart:}

Heart of duck generally showed deposition of fibrinous exudate with extravasated red blood cells in pericardium. Granulomatous pericarditis, myocarditis, edema in endocardium were observed. By IHC, the heart showed moderate positive brown immunolabelling (score +2$)$ for $P$. multocida capsular type A antigen in myocardium (Fig. 9A-D).

\section{Spleen:}

Spleen of duck showed severe depletion of lymphocytes from lymphoid follicles and hyperplasia of reticulocytes, necrosis and karyorhexis of leukocytes with accumulation of heterophilic exudate was noticed in red pulp. Focal fibrin deposition was also noticed in red pulp. By IHC, Spleen showed moderate positive brown immunolabelling $($ score +2$)$ for P. multocida capsular type A antigen free inside red pulp (Fig. 9E\&F).

\section{Proventriculus:}

Proventriculus of duck showed necrosis of tips of glandular epithelial lining gastric glands with presence of basophilic bacterial colonies. Multiple granulomata in muscular layer and serosa were found consisted of necrosis of muscle fibers surrounded by lymphocytes, macrophages and Langhan's giant cells. Focal area of dystrophic calcification was seen. By IHC, proventriculus of duck showed strong positive brown immunolabelling (score +3 ) for $P$. multocida capsular type A antigen inside glandular mucosa (Fig. $10 \mathrm{~A} \& \mathrm{~B})$

\section{Gizzard:}

Gizzard of duck showed focal area of erosion in gastric mucosa and multiple granulomata in muscular layer consisted of necrosis surrounded by lymphocytes, macrophages and Langhan's giant cells. By IHC, gizzard of duck showed strong positive brown immunolabelling (score +3 ) for $P$. multocida capsular type A antigen inside muscular layer (Fig. $10 \mathrm{C} \& \mathrm{D})$

\section{Small intestine:}

Small intestine of duck showed loss of the villi with denuded lamina propria. Leukocytic cells infiltration mainly eosinophils and few lymphocytes were observed particularly around destructed crypts of Lieberkühn with presence of desquamated necrotic epithelial cells, leukocytes and bacterial colonies inside intestinal lumen. By IHC, Small intestine of duck demonstrated strong positive brown immunolabelling (score +3 ) for P. multocida capsular type A antigen inside villi, lamina propria and among crypts of Lieberkühn (Fig. 10E\&F).

\section{Brain:}

Cerebral hemisphere of duck showed focal gliosis in brain substance, perivascular lymphocytic cuffing in Virchow-Robin space and congested blood vessels with hemolyzed blood. By IHC, cerebral 
hemisphere showed strong positive brown immunolabelling (score +3 ) for P.multocida capsular type A antigen in brain substance (Fig. 11A\&B).

\section{Skin of foot pad:}

Skin of foot pad in duck showed marked hyperkeratosis, multiple granulomata in epidermis and dermis which extended to subcutaneous muscle consisted of necrosis surrounded by lymphocytes, macrophages and Langhan's giant cells. The epidermis showed intraepithelial edema and vacuolation. By IHC, the skin of foot pad showed strong positive brown immunolabelling $($ score +3$)$ for $P$. multocida capsular type A antigen in dermis (Fig. 11C\&D).

\section{Hock joint:}

Hock joint of duck showed ulceration of epiphyseal cartilage covered with fibrinous and heterophilic exudates that also present inside the joint cavity. By IHC, hock joint of duck shows moderate positive brown immunolabelling $($ score +2$)$ for $P$. multocida capsular type A antigen in ulcerated surface and fibrinous exudates (Fig. 11E\&F).

Finally, age susceptibility, mortality rate, gross findings, histopathological and immunohistochemical examination were compared between chickens and ducks infected with $P$. multocida in (Table 3 ).

Table (1): Oligonucleotide primers sequences

\begin{tabular}{|c|c|c|c|}
\hline Target & Primers sequences & $\begin{array}{c}\text { Amplified segment } \\
\text { base airs (bp) }\end{array}$ & Reference \\
\hline \multirow[t]{2}{*}{ Kmtl } & ATC-CGC-TAT-TTA-CCC-AGT-GG & 460 & \multirow[t]{12}{*}{ OIE (2012) } \\
\hline & GCT-GTA-AAC-GAA-CTC-GCC-AC & & \\
\hline \multirow[t]{2}{*}{ Serogroup A } & TGC-CAA-AAT-CGC-AGT-GAG & \multirow[t]{2}{*}{1044} & \\
\hline & TTG-CCA-TCA-TTG-TCA-GTG & & \\
\hline \multirow[t]{2}{*}{ Serogroup B } & CAT-TTA-TCC-AAG-CTC-CAC-C & \multirow[t]{2}{*}{760} & \\
\hline & GCC-CGA-GAG-TTT-CAA-TCC & & \\
\hline \multirow[t]{2}{*}{ Serogroup D } & TA-CAA-AAG-AAA-GAC-TAG-GAG-CCC & \multirow[t]{2}{*}{657} & \\
\hline & CAT-CTA-CCC-ACT-CAA-CCA-TAT-CAG & & \\
\hline \multirow[t]{2}{*}{ Serogroup E } & TCC-GCA-GAA-AAT-TAT-TGA-CTC & \multirow[t]{2}{*}{511} & \\
\hline & GCT-TGC-TGC-TTG-ATT-TTG-TC & & \\
\hline \multirow[t]{2}{*}{ Serogroup F } & AAT-CGG-AGA-ACG-CAG-AAA-TCA-G & \multirow[t]{2}{*}{851} & \\
\hline & TTC-CGC-CGT-CAA-TTA-CTC-TG & & \\
\hline \multirow[t]{2}{*}{ toxA } & CTTAGATGAGCGACAAGG & \multirow[t]{2}{*}{864} & \multirow{2}{*}{$\begin{array}{c}\text { Tang et al., } \\
\text { (2009) }\end{array}$} \\
\hline & GAATGCCACACCTCTATAG & & \\
\hline
\end{tabular}

Table (2): Number, age and mortality rate \% of FC infected chicken and duck

\begin{tabular}{|c|c|c|c|c|c|c|c|c|c|c|}
\hline $\begin{array}{l}\text { Criteria } \\
\text { Species } \\
\text { of bird }\end{array}$ & $\begin{array}{l}\text { No. of } \\
\text { positively } \\
\text { affected } \\
\text { flocks }\end{array}$ & $\begin{array}{l}\text { No. of } \\
\text { bird/ } \\
\text { flocks }\end{array}$ & $\begin{array}{l}\text { Age } \\
\text { (days) }\end{array}$ & $\begin{array}{c}\text { Total } \\
\text { number of } \\
\text { dead birds } \\
\text { per flock }\end{array}$ & $\begin{array}{c}\text { Mortality } \\
\text { rate } \%\end{array}$ & Breed & Date & $\begin{array}{c}\text { Housing } \\
\text { type }\end{array}$ & $\begin{array}{c}\text { No. of } \\
\text { positive } \\
\text { birds }\end{array}$ & Total \\
\hline \multirow[t]{9}{*}{ Chicken } & 1 & 11000 & 150 & 27 & 0.25 & Layer & July-2014 & \multirow[t]{9}{*}{ Farm } & 5 & \multirow[t]{9}{*}{22} \\
\hline & 2 & 5000 & 30 & 18 & 0.36 & Broiler & March-2015 & & 2 & \\
\hline & 3 & 6000 & 54 & 10 & 0.22 & Broiler & Nov- 2015 & & 2 & \\
\hline & 4 & 13000 & 50 & 12 & 0.17 & Broiler & Nov- 2015 & & 1 & \\
\hline & 5 & 12000 & 70 & 15 & 0.09 & Breeder & Nov- 2015 & & 2 & \\
\hline & 6 & 17000 & 150 & 20 & 0.1 & Breeder & Nov- 2015 & & 3 & \\
\hline & 7 & 14500 & 130 & 5 & 0.12 & Layer & Nov- 2015 & & 2 & \\
\hline & 8 & 5000 & 150 & 12 & 0.03 & Layer & Nov- 2015 & & 2 & \\
\hline & 9 & 10000 & 45 & 7 & 0.24 & Layer & May-2016 & & 3 & \\
\hline \multirow[t]{3}{*}{ Duck } & 1 & 2000 & 100 & 25 & 0.8 & Broiler & Nov-2015 & Farm & 7 & \multirow{3}{*}{16} \\
\hline & 2 & 30 & 35 & 10 & 33.3 & Broiler & June-2015 & \multirow{2}{*}{$\begin{array}{l}\text { Back- } \\
\text { yard }\end{array}$} & 5 & \\
\hline & 3 & 15 & 30 & 7 & 46.6 & Broiler & Dec-2015 & & 4 & \\
\hline Total & 12 & & & & & & & & & 38 \\
\hline
\end{tabular}


Table (3): Age susceptibility, mortality rate, gross findings, histopathological and immunohistochemical examination in chickens and ducks infected with $P$. multocida

\begin{tabular}{lll}
\hline \multicolumn{1}{c}{ Criteria } & Chicken & Duck \\
\hline Age & $30-150$ days & $30-100$ days \\
\hline Mortality rate\% & $0.03-0.36$ & $0.8-46.6$ \\
\hline
\end{tabular}

\begin{tabular}{lll}
\hline & \multicolumn{2}{c}{ Gross lesions } \\
\hline Edema in face & + & - \\
\hline $\begin{array}{l}\text { Petechial } \\
\text { hemorrhage on } \\
\text { coronary fat }\end{array}$ & + & slightly cloudy \\
\hline Peritoneum & Fibrinous peritonitis and visceral adhesion & Few pin point grayish white foci on surface \\
\hline Corn meal liver & Numerous pin point grayish white foci on surface & Not apparent \\
\hline Small intestine & congested serosal blood vessels & swollen \\
\hline Hock joint & normal not collected & thickened \\
\hline Skin of footpad & normal not collected &
\end{tabular}

Microscopic lesions and IHC scores

\begin{tabular}{|c|c|c|}
\hline Trachea & focal loss of epithelial lining (IHC score 0 ) & $\begin{array}{l}\text { focal loss of epithelial lining with multiple } \\
\text { granulomata (IHC score 3) }\end{array}$ \\
\hline Lung & $\begin{array}{l}\text { Fibrinous pneumonia with focal necrotic area and } \\
\text { granuloma (IHC score } 2 \text { ) }\end{array}$ & $\begin{array}{l}\text { fibrinopurulent pleuropneumonia with focal } \\
\text { granuloma (IHC score 3) }\end{array}$ \\
\hline Liver & $\begin{array}{l}\text { Fibrinous perihepatitis, multiple areas of coagulative } \\
\text { necrosis, angiopathy with hemolyzed blood (IHC } \\
\text { score } 3 \text { ) }\end{array}$ & $\begin{array}{l}\text { granuloma and focal areas of coagulative necrosis } \\
\text { (IHC score 2) }\end{array}$ \\
\hline Heart & $\begin{array}{l}\text { Fibrinous or fibrinopurulent pericarditis with } \\
\text { myocarditis (IHC score 0) }\end{array}$ & $\begin{array}{l}\text { granulomatous pericarditis and myocarditis (IHC } \\
\text { score 2) }\end{array}$ \\
\hline Spleen & $\begin{array}{l}\text { Splenitis with edema and moderate to severe } \\
\text { depletion lymphocytes from the lymphoid follicles in } \\
\text { white pulp that replaced by heterophiles (IHC score 1) }\end{array}$ & $\begin{array}{l}\text { Splenitis with severe depletion lymphocytes from } \\
\text { the lymphoid follicles in white pulp that replaced } \\
\text { by reticulocytes (IHC score } 2 \text { ) }\end{array}$ \\
\hline Kidney & $\begin{array}{l}\text { Congestion, hemorrhage and focal to diffuse } \\
\text { coagulative necrosis (IHC score } 1 \text { ) }\end{array}$ & $\begin{array}{l}\text { diffuse coagulative necrosis associated with } \\
\text { presence of basophilic bacterial colonies (IHC } \\
\text { score 3) }\end{array}$ \\
\hline Proventriculus & $\begin{array}{l}\text { necrosis and sloughing of surface epithelium with } \\
\text { desquamation of glandular epithelium (IHC score } 0 \text { ) }\end{array}$ & $\begin{array}{l}\text { necrosis of tips of glandular epithelium associated } \\
\text { with basophilic bacterial colonies and multiple } \\
\text { granulomata in wall (IHC score } 3 \text { ) }\end{array}$ \\
\hline Gizzard & $\begin{array}{l}\text { necrosis of surface epithelium with atrophied gastric } \\
\text { glands (IHC score } 0 \text { ) }\end{array}$ & $\begin{array}{l}\text { erosion in gastric mucosa and multiple } \\
\text { granulomata (IHC score 3) }\end{array}$ \\
\hline Small intestine & $\begin{array}{l}\text { atrophy and fusion of villi with fibrinous peritonitis } \\
\text { (IHC score } 0 \text { ) }\end{array}$ & $\begin{array}{l}\text { enteritis with leukocytic cells infiltration (IHC } \\
\text { score } 3 \text { ) }\end{array}$ \\
\hline
\end{tabular}



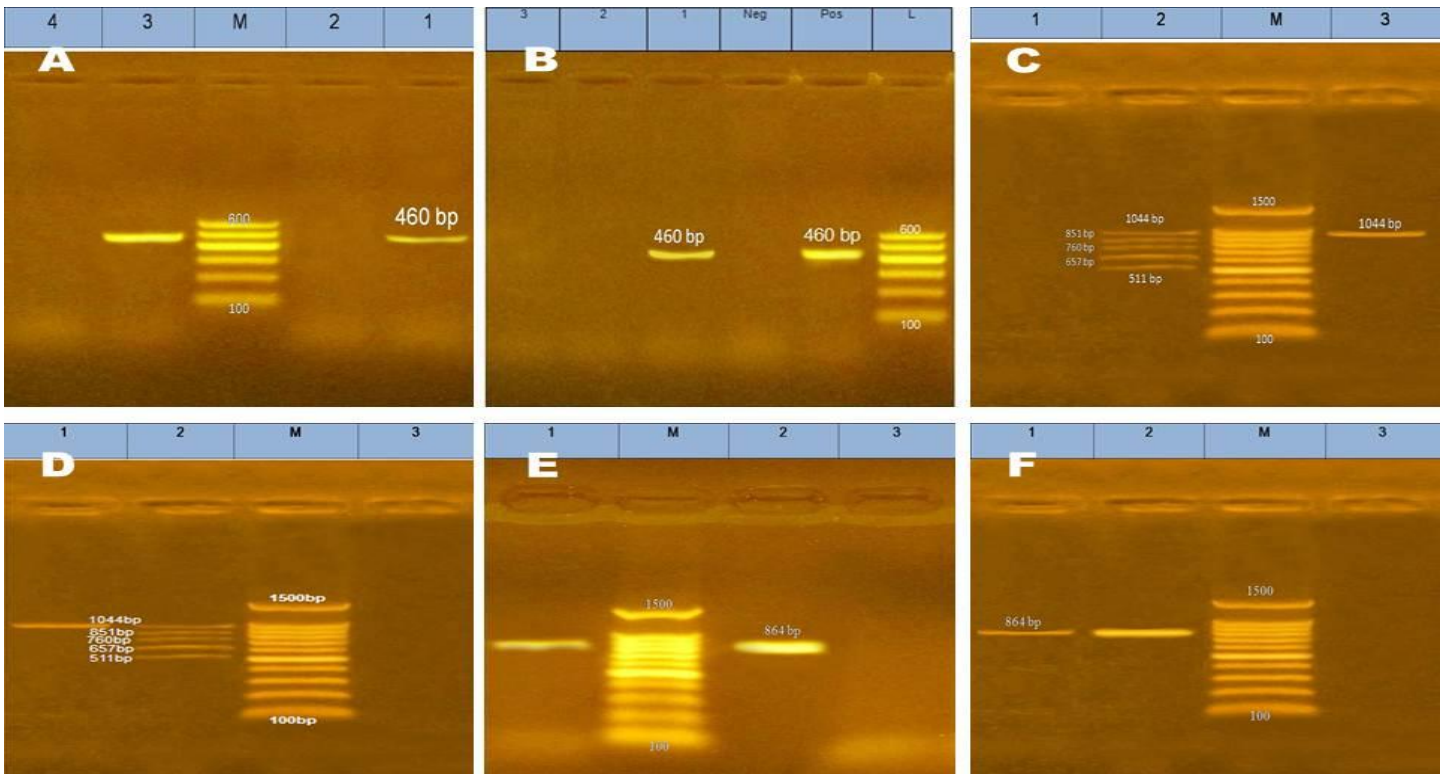

Fig. 1: Agarose gel electrophoresis (1.4\%) of (A): the uniplex PCR (kmt 1$)$ gene product of $P$. multocida of 2 chicken samples Lane M 100 bp DNA ladder, lane 1: positive chicken isolate, lane 2: negative chicken isolate, lane 3: positive control, lane 4: negative control. (B): the uniplex PCR $(\mathrm{kmtl})$ gene product of $P$. multocida of 3duck samples. Lane L $100 \mathrm{bp}$ DNA ladder, lane 1: positive duck isolate, lane 2, 3: negative duck isolate, lane pos: positive control, lane neg: negative control. (C): the multiplex capsular PCR typing product of chicken isolate. Lane 1: negative control, lane 2: positive control samples for capsule type A(1044bp), B(760bp), D(657bp), E(511bp), F(851bp), lane M: marker, 100 bp DNA ladder, lane 3: positive chicken isolate. (D): the multiplex capsular PCR typing product of duck isolate. Lane 1: duck isolate, lane 2: positive control samples for capsule type A(1044bp), B(760bp), D(657bp), E(511bp), F(851bp). lane M: marker, 100 bp DNA ladder, lane 3: negative control. (E): the uniplex PCR tox A gene product of chicken isolate. Lane 1: chicken sample, lane M: marker, 100 bp DNA ladder, lane 2: positive control samples. lane 3: negative control. (F): the uniplex PCR tox A gene product of duck isolate. Lane 1: positive duck sample, lane M: marker, $100 \mathrm{bp}$ DNA ladder, lane 2: positive control samples. lane 3: negative control.
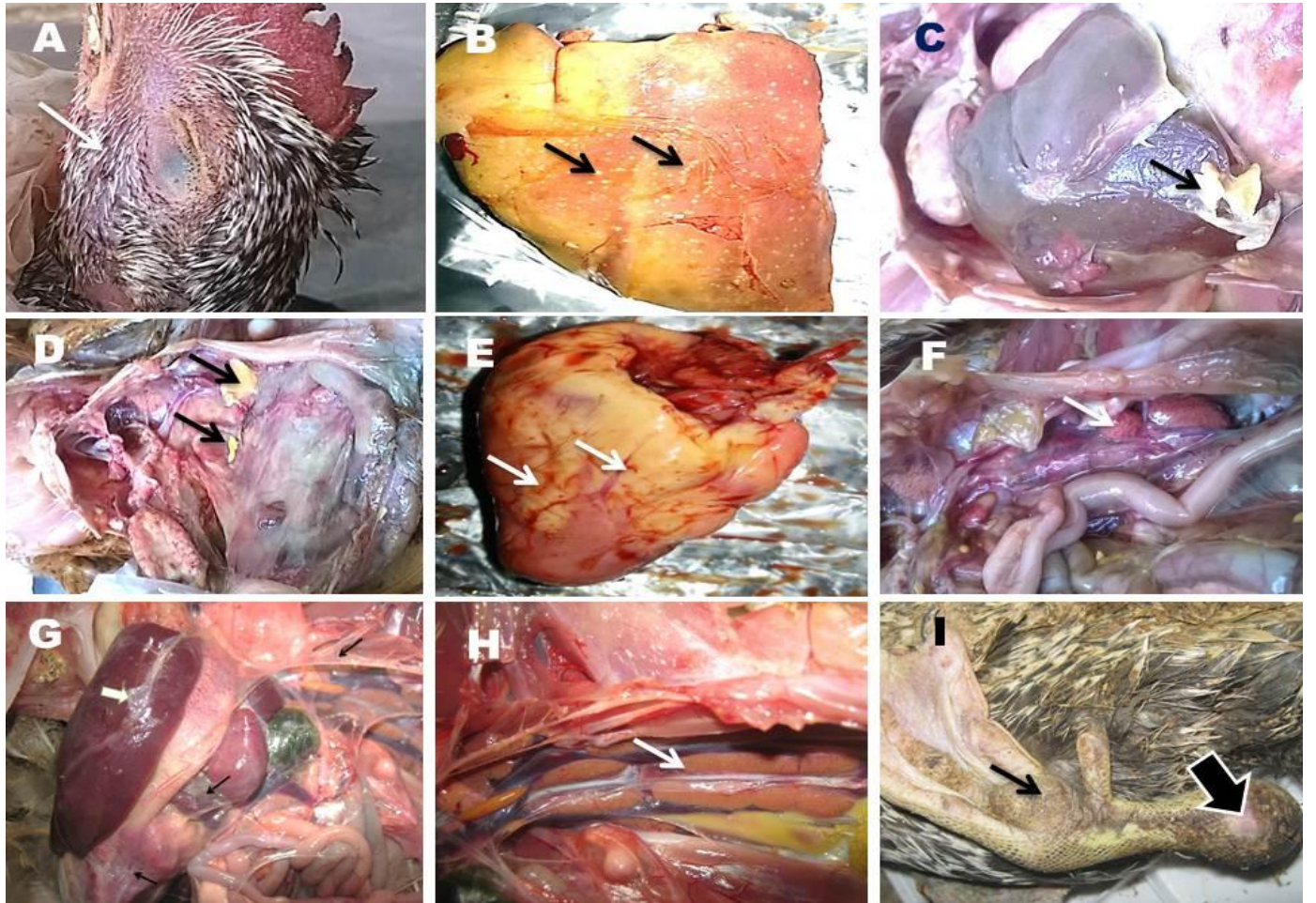

Fig. 2: Infected chicken shows (A) edematous face (arrow), (B) discrete pin point whitish foci of coagulative necrosis in liver (corn meal liver) (arrows) with friable texture, pointed borders and torn capsule, (C) congested liver with fibrinous perihepatitis (arrow), (D) fibrinous peritonitis (arrows), (E) petechial hemorrhages on coronary fat (arrows) and (F) congested kidneys (arrow). Infected ducks shows (G): fibrinous perihepatitis (thick arrow) and cloudy or opaque air sacs and peritoneum (thin arrows). (H): pale kidneys (arrow) and (I): swollen hock joint (thick arrow) with thickening in the skin of footpad (thin arrow). 

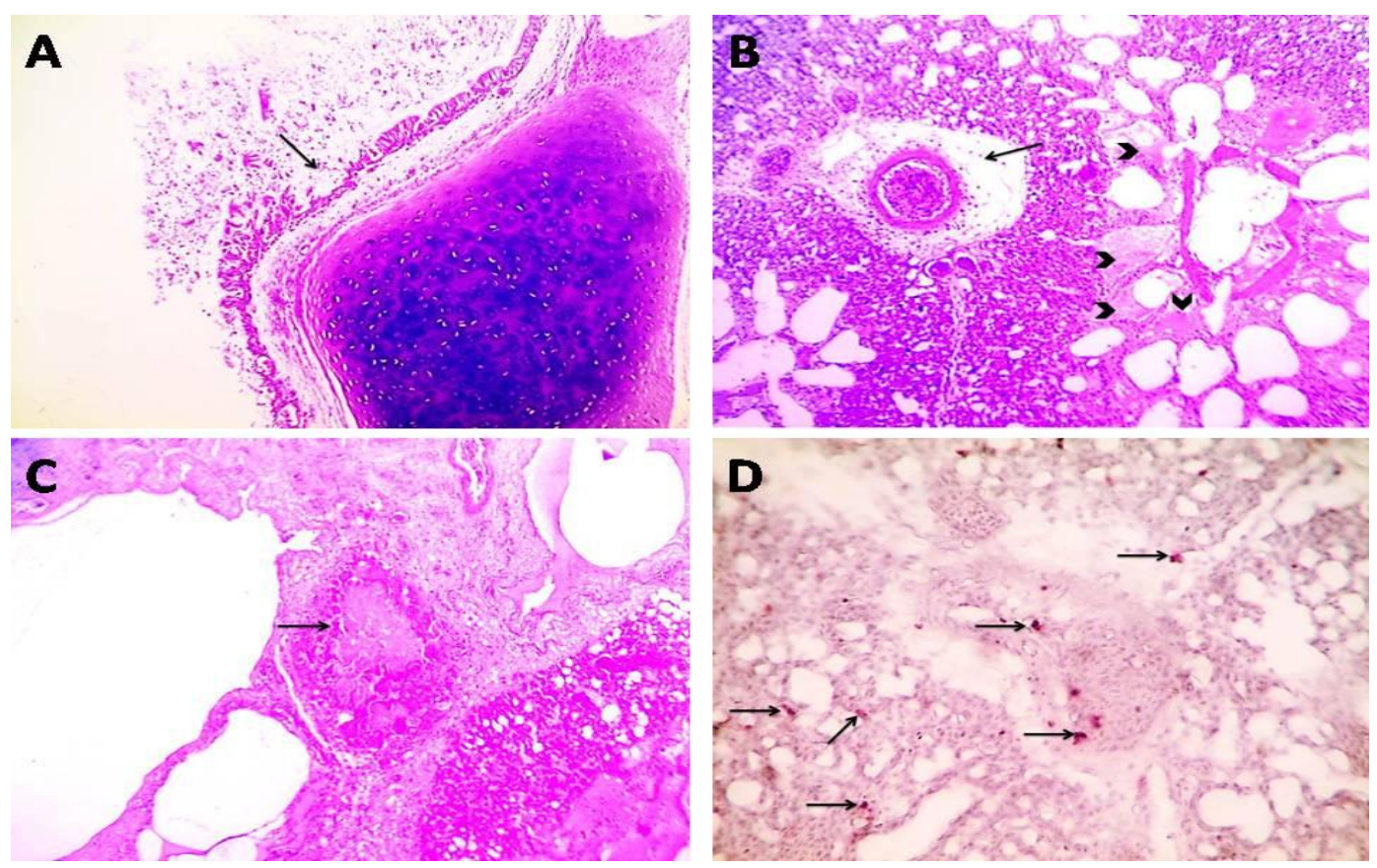

Fig. 3: Trachea of chicken shows (A) focal loss of epithelial lining (arrow). H\&E, X: 100. Lung of chicken shows (B) perivascular edema (arrow) with presence of pale eosinophilic edematous fluid inside air alveoli (arrowheads) (H\&E, X: 100), (C) focal replacement of pulmonary parenchyma with granuloma (arrow) consisted of central necrotic area surrounded by leukocytes and giant cells. H\&E, X: 100 and (D) moderate positive brown immunolabelling (score +2 ) for $P$. multocida capsular type A antigen inside blood in blood vessels and interalveolar capillaries (arrows) (IHC counterstained with hematoxylin, X: 100).
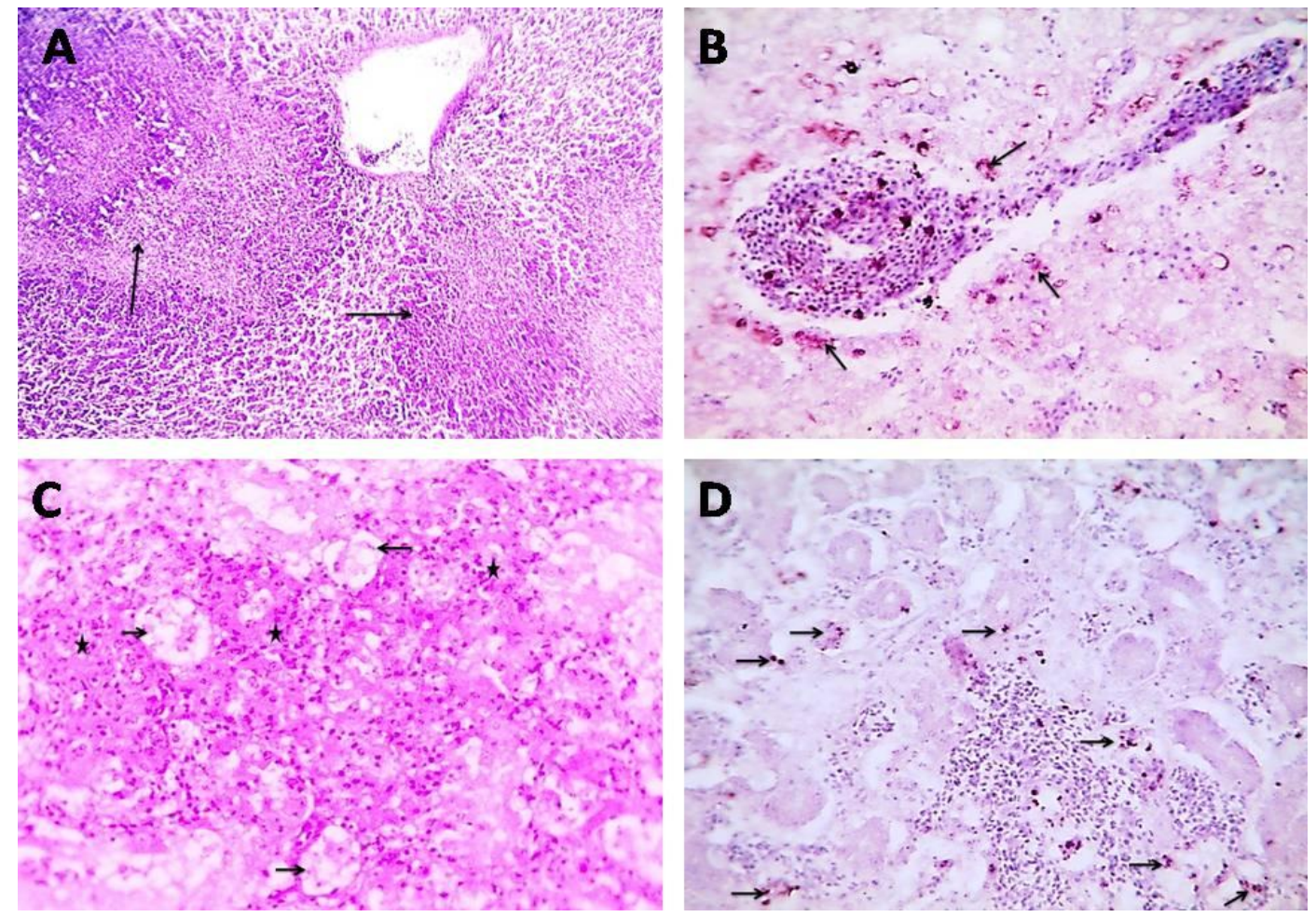

Fig. 4: Liver of chicken shows (A) multifocal areas of coagulative necrosis (arrows) (H\&E, X: 100) and (B) strong positive brown immunolabelling $($ score +3 ) for $P$. mulocida capsular type A antigen perivascular inside hepatocytes and inside blood (arrows) (IHC counterstained with hematoxylin, X: 200). Kidneys of chicken shows (C) focal coagulative necrosis of renal tubules (arrows) which infiltrated with heterophils (asterisks) (H\&E, X: 200) and (D) weak positive brown immunolabelling (score +1) for P. multocida capsular type A antigen inside blood and renal tubules (arrows) (IHC counterstained with hematoxylin, X: 200). 

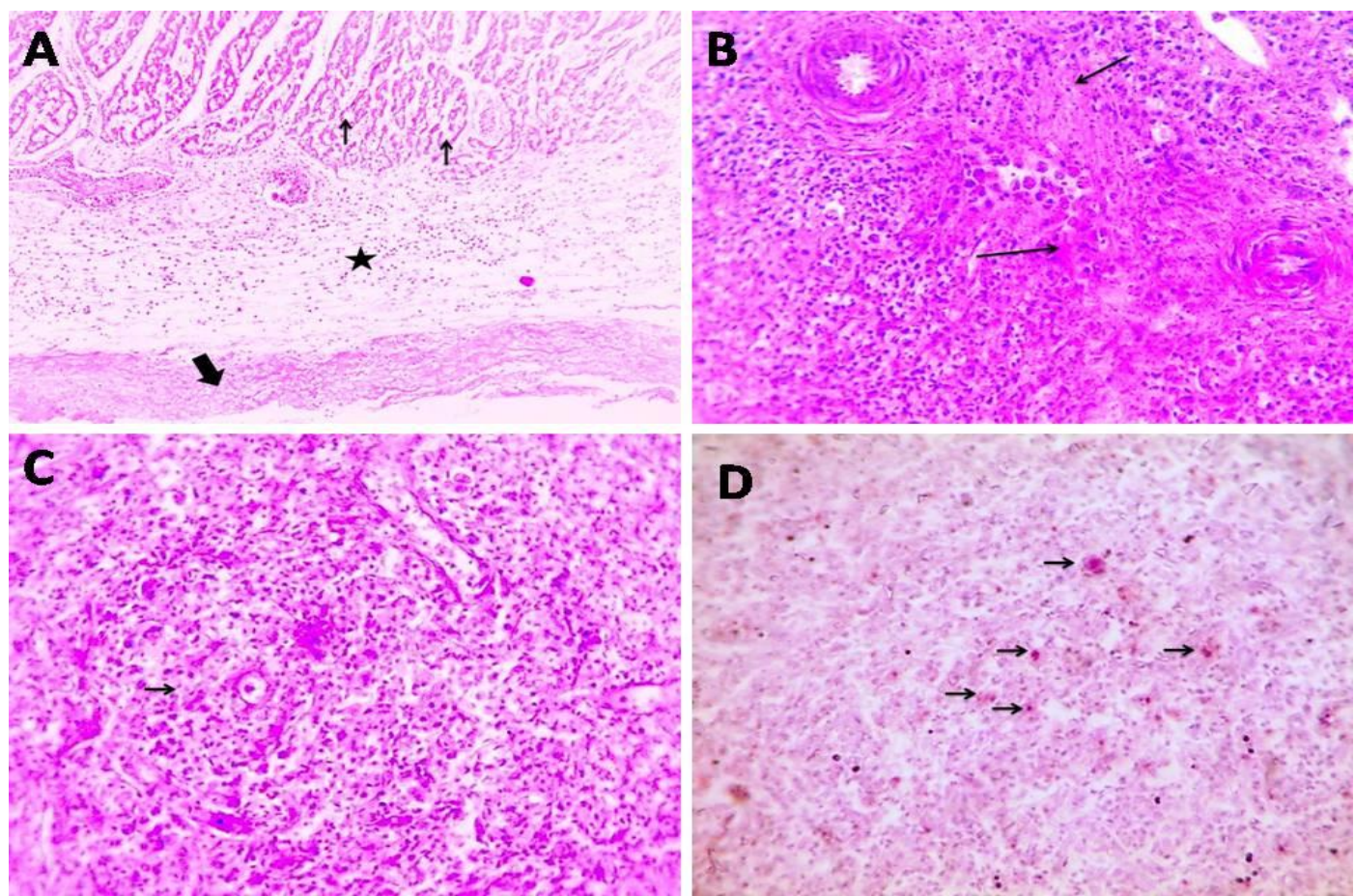

Fig. 5: Heart of chicken shows (A) fibrinopurulent pericarditis characterized by marked edema (asterisk), numerous heterophils and deposition of pale eosinophilic fibrin threads (thick arrow), besides congested capillaries and severe vacuolation in cardiac muscle fibers (thin arrows). H\&E, X: 100. Spleen of chicken shows (B) perivascular necrosis and fibrosis with aggregation of heterophiles and bacterial coccobacilli around central arterioles (arrows). H\&E, X: 200, (C) depletion of lymphocytes from white pulp (arrow). H\&E, X: 200 and (D) weak positive brown immunolabelling (score +1 ) for $P$. multocida capsular type A antigen inside red pulp (arrows). IHC counterstained with hematoxylin.
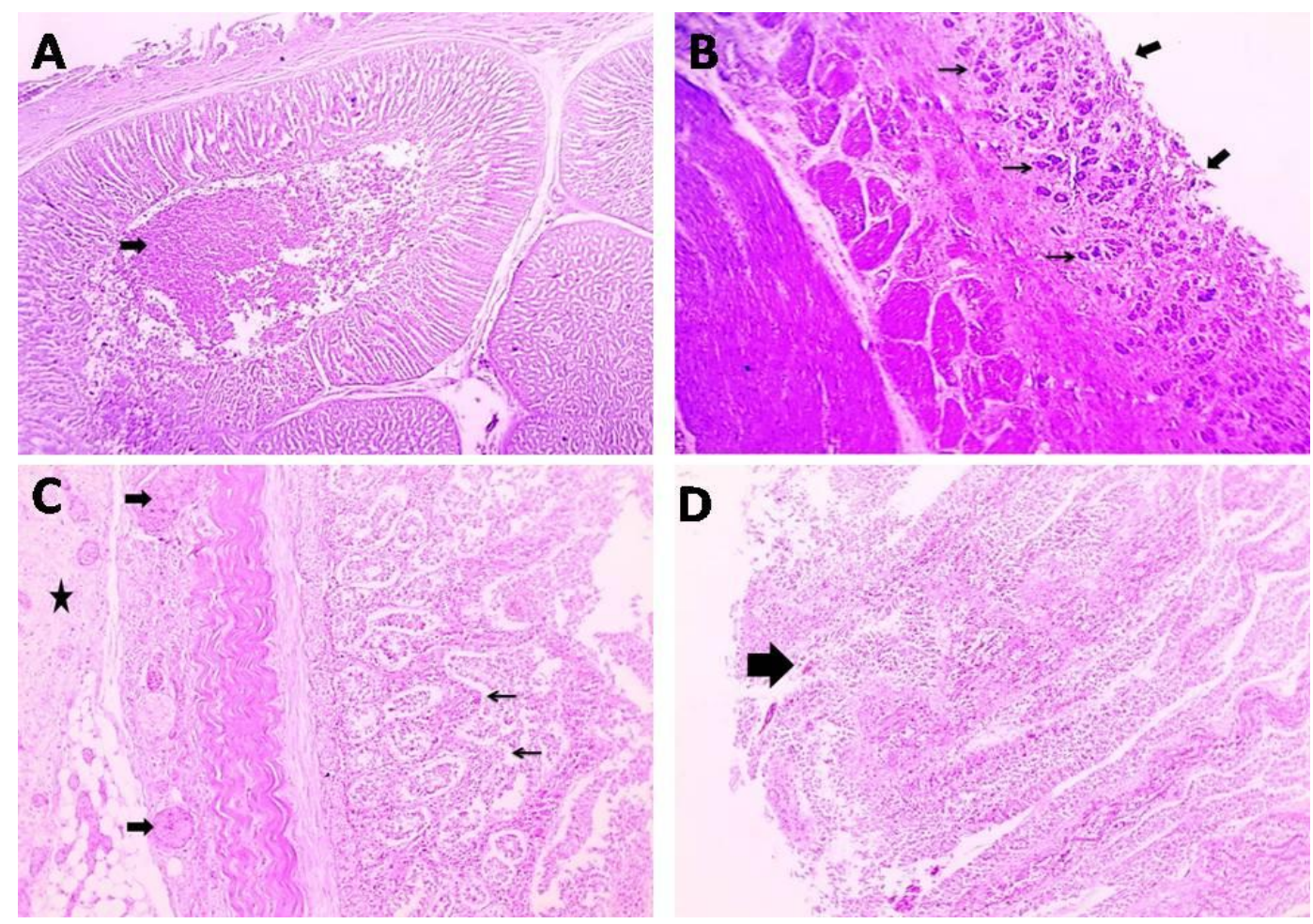

Fig. 6: Proventriculus of chicken shows (A) desquamation of glandular epithelium inside the lumen of gastric glands (thick arrow). H\&E, X: 50. Gizzard of chicken shows (B) necrosis of surface epithelium (thick arrows) with atrophied gastric glands in lamina propria (thin arrows). H\&E, X: 50. Small intestine of chicken shows (C) atrophy of villi (thin arrows), congested serosal blood vessels (thick arrows) and eosinophilic fibrin deposition on serosal covering (asterisks). H\&E, X: 50 and (D) fusion of intestinal villi (thick arrow). H\&E, X: 100 

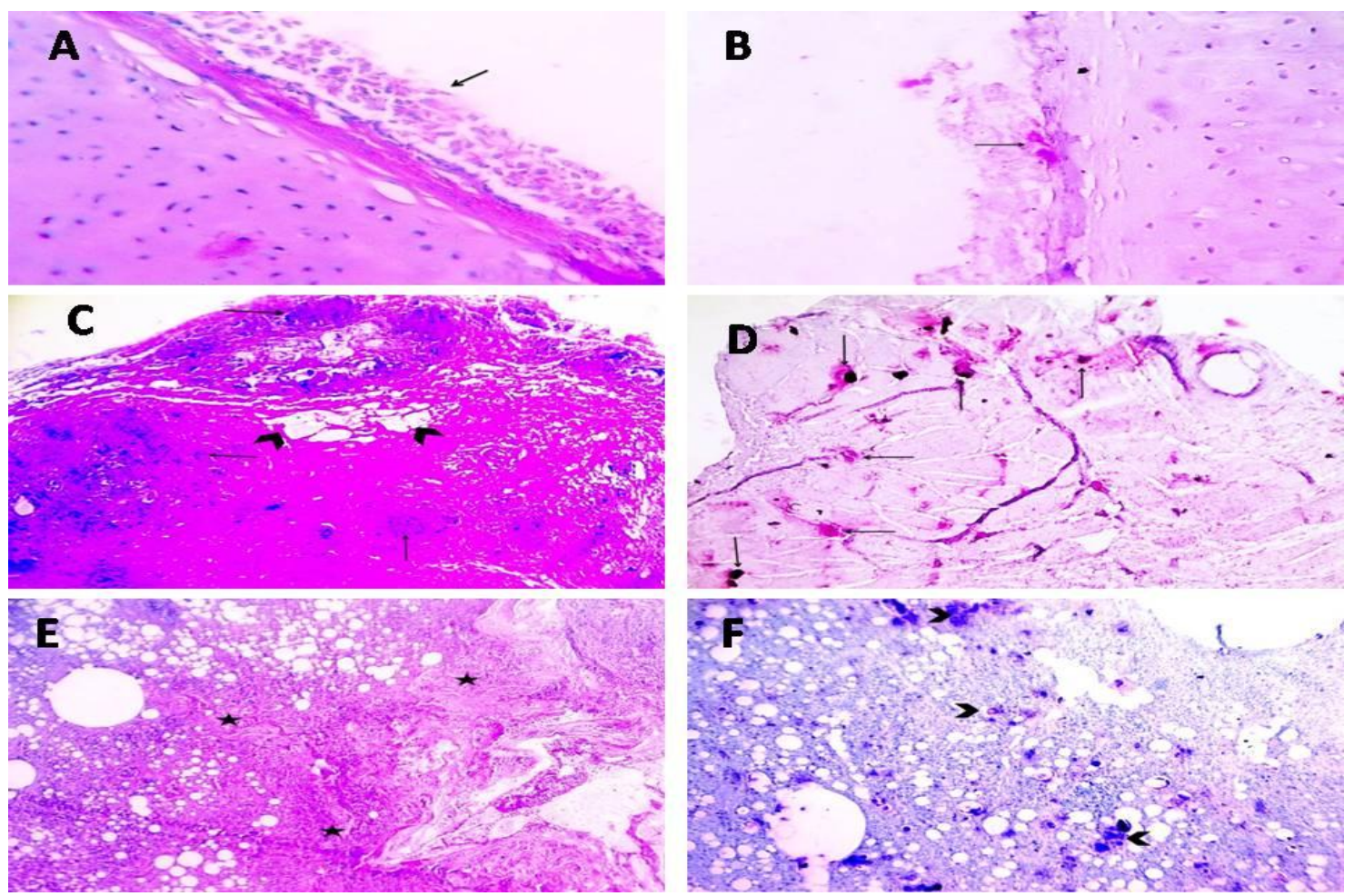

Fig. 7: (A-D): Trachea of duck shows (A) necrosis of epithelial lining (arrow) (H\&E, X: 200), (B) weak positive brown immunolabelling (score +1) for P. multocida capsular type A antigen in necrotic epithelial lining (arrow) (IHC counterstained with hematoxylin, X: 200), (C) multiple granulomata in wall and serosa (arrows) with dilated lymphatics around granulomata (arrowheads) (H\&E, X: 100) and (D) strong positive brown immunolabelling (score +3) for P. multocida capsular type A antigen in muscular layer of tracheal wall (arrows) (IHC counterstained with hematoxylin, X: 100). Lung of duck shows (E) fibrinous exudate, leukocytic cells infiltration besides basophilic bacterial colonies replaced pulmonary parenchyma (asterisks) (H\&E, X: 100) and (F) strong positive brown immunolabelling (score +3 ) for $P$. multocida capsular type A antigen in pulmonary parenchyma (arrowheads) (IHC counterstained with hematoxylin, $\mathrm{X}: 100)$.
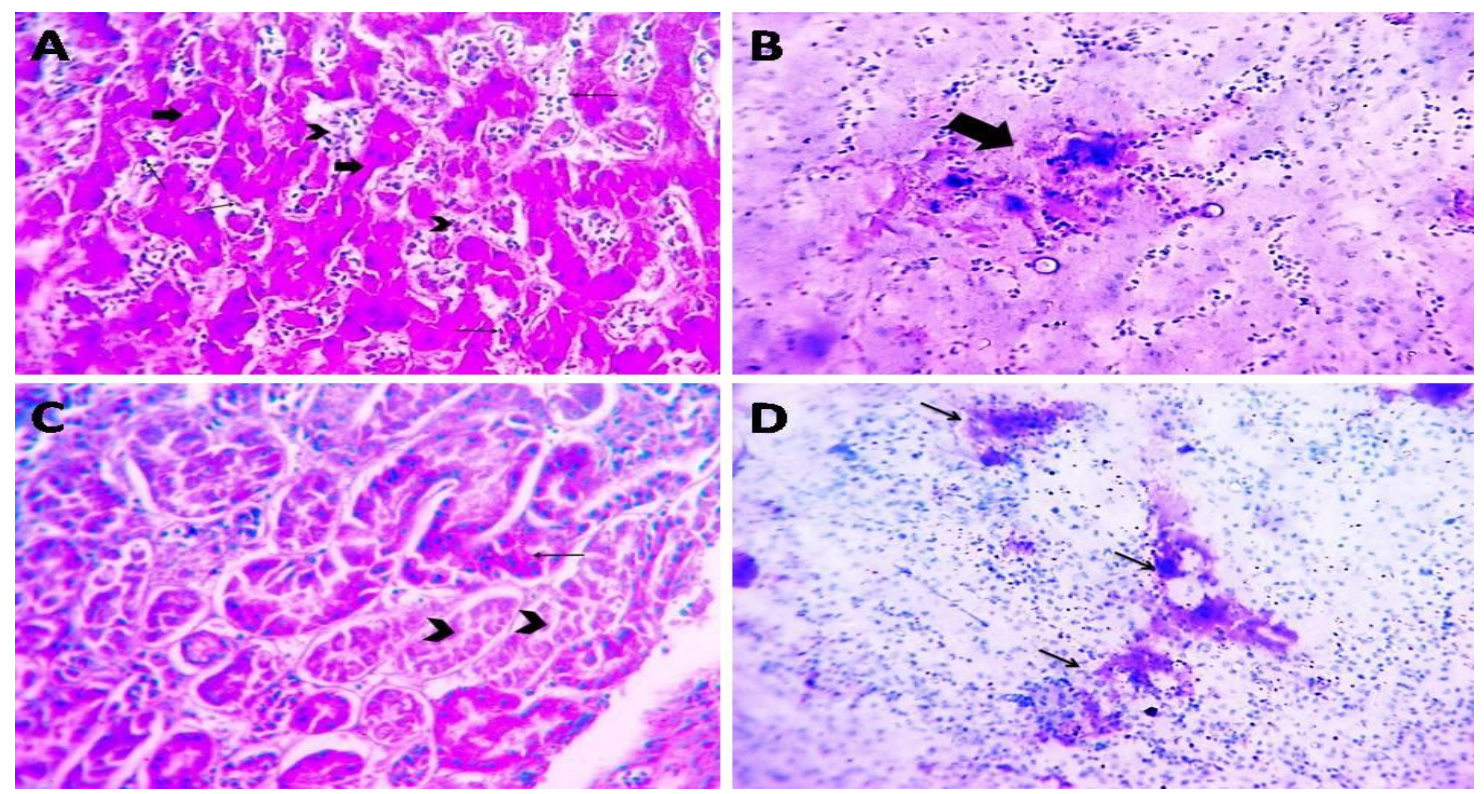

Fig. 8: Liver of duck shows (A) coagulative necrosis in hepatocytes (thick arrows) with dilated sinusoids (arrowheads) and hypertrophied von Kupffer cells (thin arrows) (H\&E, X: 200) and (B) moderate positive brown immunolabelling (score +2 ) for P. multocida capsular type A antigen inside affected hepatic parenchyma (arrow) (IHC counterstained with hematoxylin, X: 200). Kidney of duck shows (C) coagulative necrosis in renal tubules with karyolysis (arrowheads) and pyknosis of nuclei (arrow) of renal tubular epithelium (H\&E, X: 200) and (D) strong positive brown immunolabelling (score +3 ) for $P$. multocida capsular type A antigen inside renal parenchyma (arrows) (IHC counterstained with hematoxylin, X: 200). 

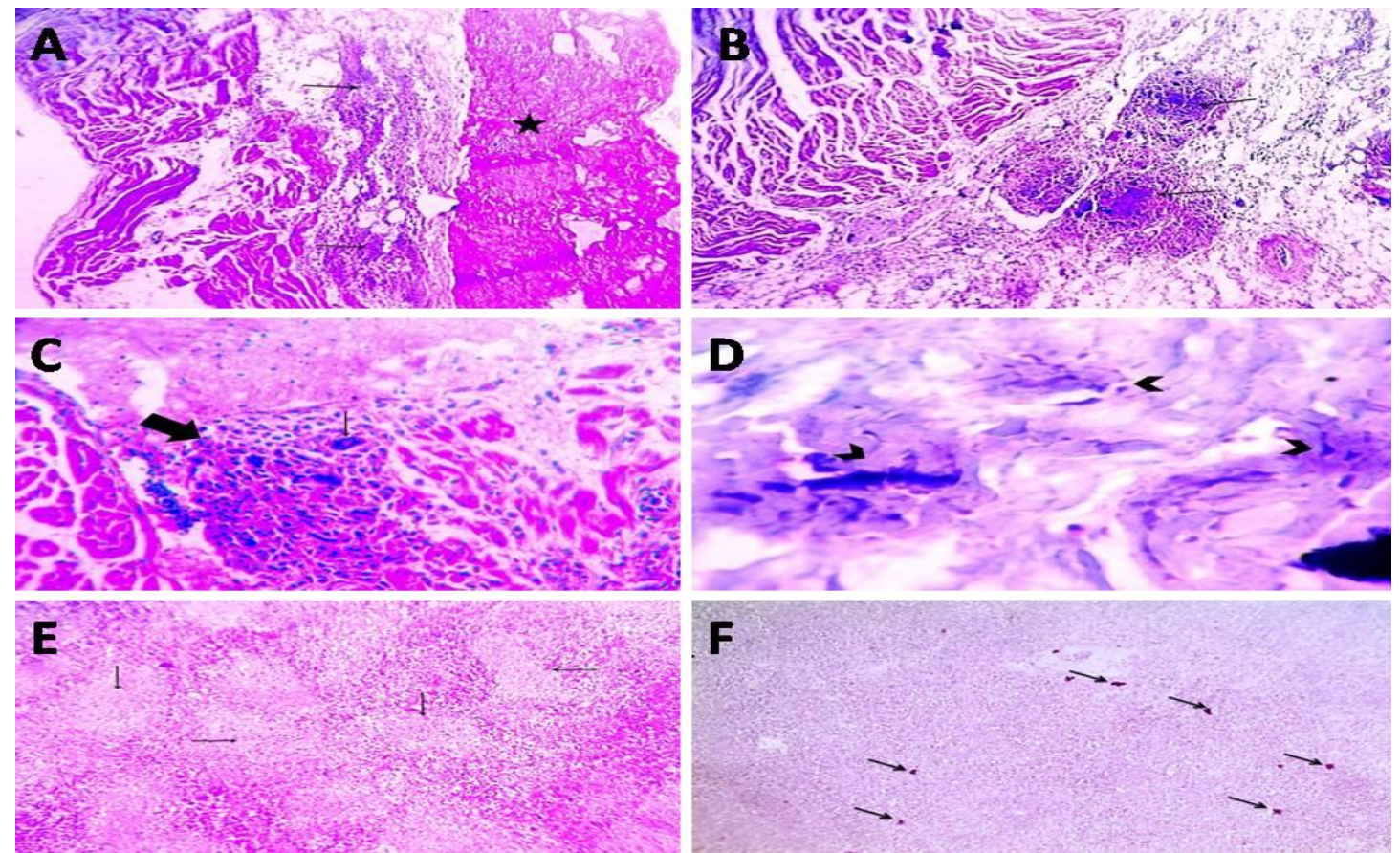

Fig. 9: Heart of duck shows (A) fibrinous pericarditis (asterisk) and hemorrhage (arrows) in the pericardium (H\&E, X: 100), (B) granulomatous pericarditis (arrows) (H\&E, X: 100), (C) granulomatous myocarditis (thick arrow) characterized by focal area of necrosis surrounded by leukocytic cells infiltration and Langhan's giant cells (thin arrow) (H\&E, X: 200) and (D) moderate positive brown immunolabelling (score +2 ) for P. multocida capsular type A antigen in myocardium (arrowheads) (IHC counterstained with hematoxylin, X: 200). Spleen of duck shows (E) severe depletion of lymphocytes from lymphoid follicles and hyperplasia of reticulocytes (arrows) (H\&E, X: 100) and (F) moderate positive brown immunolabelling (score +2 ) for P. multocida capsular type A antigen free inside red pulp (arrows) (IHC counterstained with hematoxylin, X: 100).
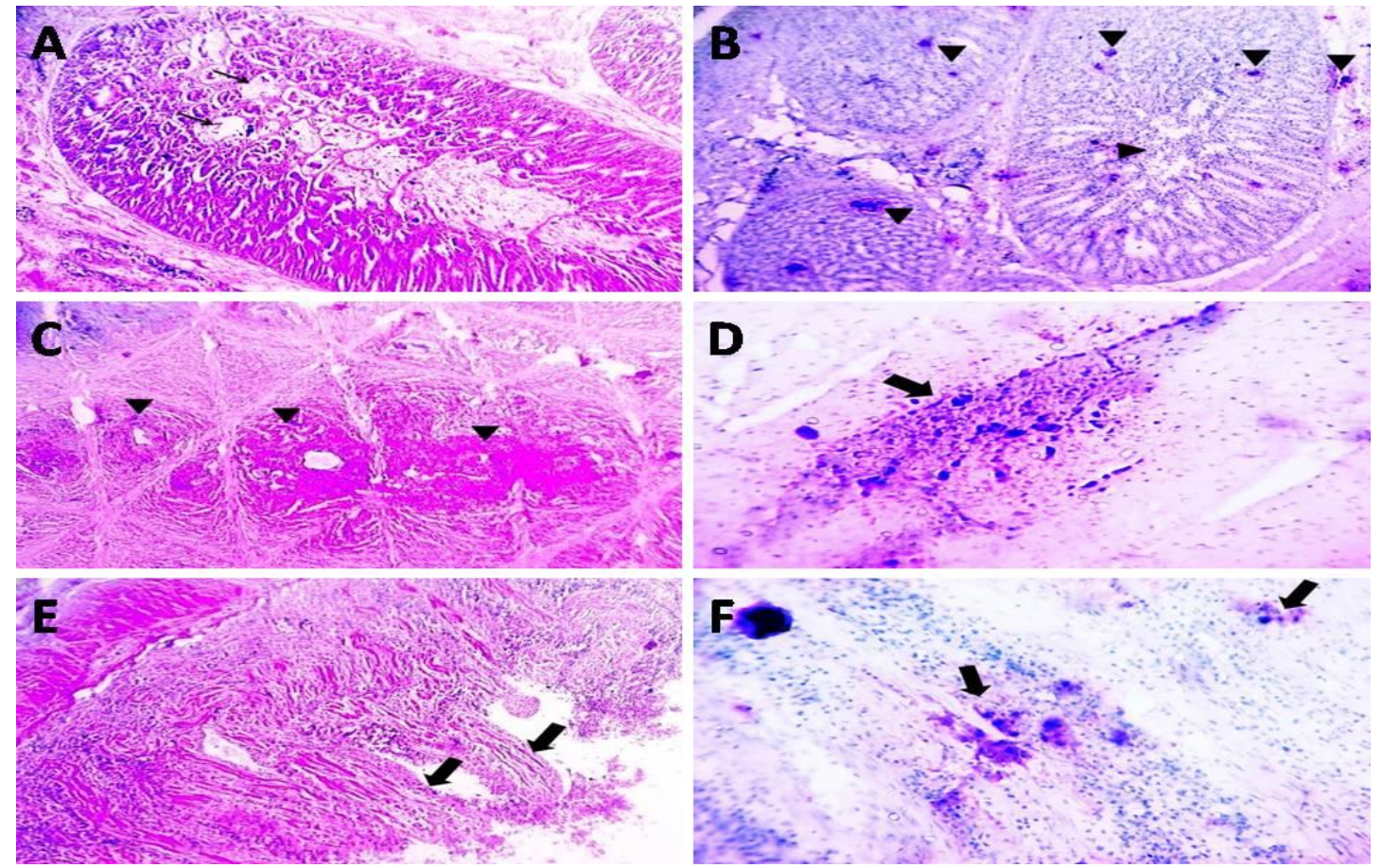

Fig. 10: Proventriculus of duck shows (A) necrosis of tips of glandular epithelial lining gastric glands (arrows) (H\&E, X: $100)$ and (B) strong positive brown immunolabelling (score +3 ) for $P$. multocida capsular type A antigen inside glandular mucosa (arrowheads) (IHC counterstained with hematoxylin, X: 100). Gizzard of duck shows (C) multiple granulomata in muscular layer consisted of necrosis surrounded by lymphocytes, macrophages and Langhan's giant cells (arrowheads) (H\&E, X: 100) and (D) strong positive brown immunolabelling (score +3) for P. multocida capsular type A antigen inside muscular layer (arrow) (IHC counterstained with hematoxylin, X: 200). Small intestine of duck shows (E) loss of villi and exposure of lamina propria (arrows) (H\&E, X: 100) and (F) strong positive brown immunolabelling (score +3 ) for $P$. multocida capsular type A antigen inside villi (arrows) (IHC counterstained with hematoxylin, X: 200). 

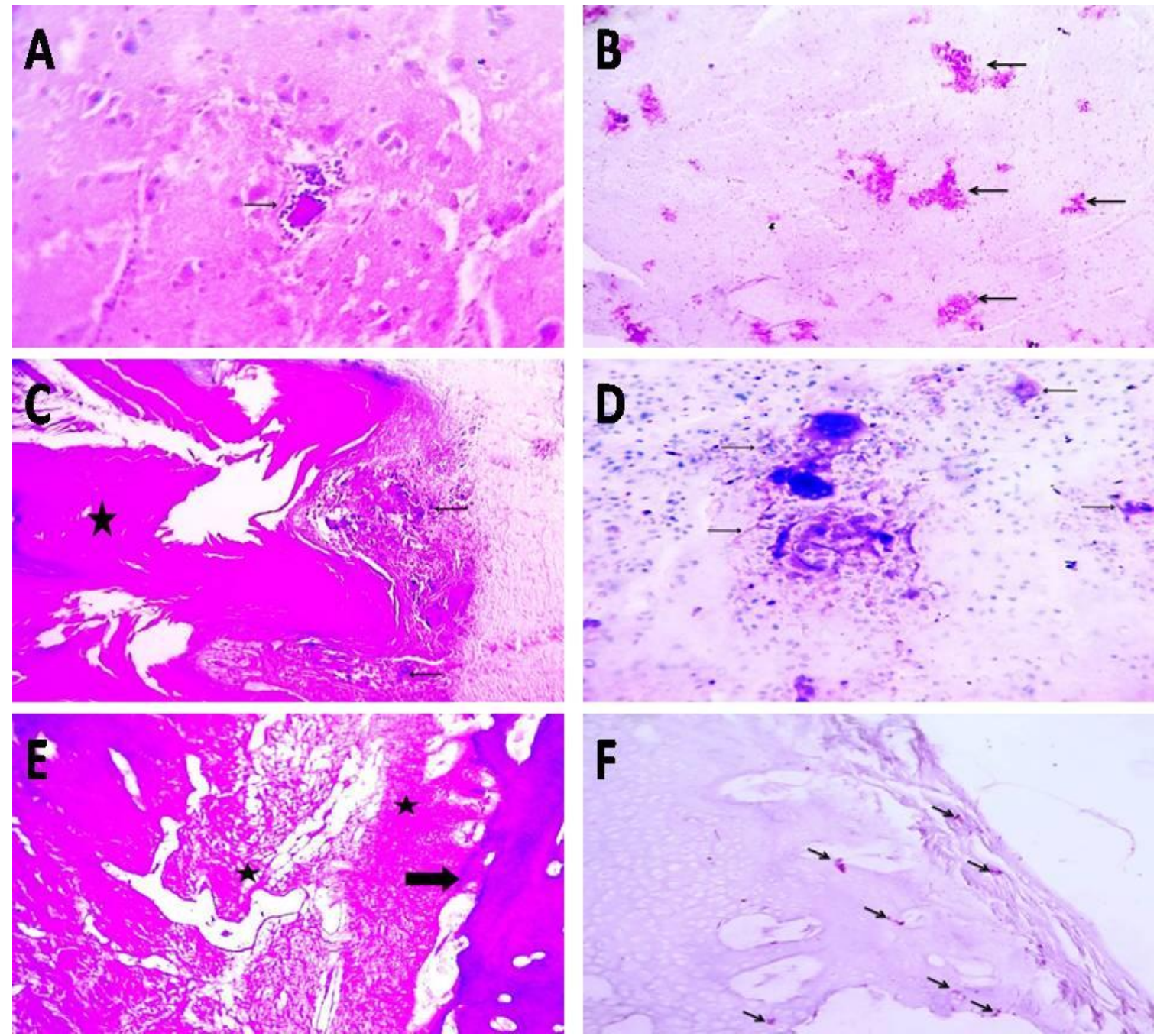

Fig. 11: Cerebral hemisphere of duck shows (A) perivascular lymphocytic cuffing (arrow) in Virchow-Robin space (H\&E, X: 200) and (B) strong positive brown immunolabelling (score +3 ) for P. multocida capsular type A antigen in brain substance (arrows) (IHC counterstained with hematoxylin, X: 100). Skin of foot pad in duck shows (C) marked hyperkeratosis (asterisk) and multiple granulomata (arrows) in epidermis and dermis (H\&E, $\mathrm{X}$ : 100) and (D) strong positive brown immunolabelling (score +3 ) for $P$. multocida capsular type A antigen in dermis (arrows) (IHC counterstained with hematoxylin, X: 200). Hock joint of duck shows (E) ulceration of epiphyseal cartilage (arrow) covered with fibrinous exudate (asterisk) (H\&E, X: 100) and (F) Hock joint of duck shows moderate positive brown immunolabelling (score +2$)$ for $P$. multocida capsular type A antigen in ulcerated surface (arrows) (IHC counterstained with hematoxylin, X: 100).

\section{DISCUSSION}

FC is a highly contagious disease caused by a bacterium called $P$. multocida causing high mortality and significant economic losses in both commercial and backyard poultry production (Christensen and Bisgaard, 2003). The great economic losses in poultry production represented by $1.8-21 \%$ mortalities and $15-20 \%$ decreases in egg production, besides, costs of treatment and vaccination (Kapetanov et al., 2000; Charitha Devi et al., 2012; Wilkie et al., 2012). The incidence of FC is on increase despite vaccination and proper medication. This can be attributed to various incriminating factors (Jonas et al., 2001; Kehrenberg et al., 2001).
PCR methods were used for specific detection of $P$. multocida on the bases of kmtl gene sequence. In this study, 5 isolates ( 2 chickens, 3 ducks) were tested by PCR, 1 chicken isolate out of 2 isolates and 1 duck isolate out of 3 isolates gave positive result for Kmt 1 gene. In the same context, Adhikary et al. (2013) clarified that only the kmtl method discovered $P$. multocida with the predictable specificity and sensitivity. Therefore, kmtl method found to be advisable for identification of $P$. multocida capsular genotyping was done on isolated strains of $P$. multocida from chicken as described by Townsend et al. (2001); OIE (2012) using six primer sets. Capsular typing process was done by using multiplex PCR. The chicken isolate was identified as 
capsular type A. Similarly, Wilson, (2001); Sellyei et al. (2008); Mohamed et al. (2012) found that $P$. multocida strains of serotype A were the most primary and dominant cause of FC, meanwhile, isolates of other serotypes (B, and $\mathrm{F}$ ) were less frequent or not associated with cause the disease. ToxA gene was detected in chicken isolate which encoding the toxic activity of only toxigenic strains of P. multocida. This was in agreement with Petersen and Foged, (1989); Lichtensteiger et al. (1996).

In the present study, 81 bird samples were collected from 22 flocks (16 for chickens, 6 for ducks) either farms or backyard. According to bacteriological isolation and PCR, P. multocida was isolated from 38 birds (22 chicken, 16 duck) with the percentage of $43 \%$ in chickens and $53 \%$ in ducks. Thus, the positive FC cases were collected from 9 chicken flocks out of 16 and from only 3 duck flocks out of 6 . The lower rates of infection in chickens were also observed by Mohamed et al. (2012) who isolated 21 isolates of P. multocida out of 275 backyard chickens (7.6\%) in Upper Egypt. Meanwhile Arshed et al. (2003) isolated $P$. multocida from 12 out of $16(75 \%)$ commercial layer flocks suspected to have FC outbreaks. Woo and Kim (2006) confirmed 40,000 FC cases out of 60,000 broiler breeder chickens in a farm in Korea (66.6\%), with 50 chickens died per day. Higher rates of infection in ducks were recently recorded by Saad Eldin and Reda (2016) who isolated P. multocida from $60 \%$ of the ducks showing respiratory manifestations and watery diarrhea at Sharkia governorate, Egypt. Afifi and El-Nesr, (2013) isolated $P$. multocida from ducks in Beni Suef Governorate, Egypt with an incidence of $40.71 \%$. The difference in infection rate was thought to be related to the total number of examined bird samples, presence of stress, method of isolation, geographic variation, age of the diseased birds, poor management and resistant power of backyard chickens in Upper Egypt (breed).

It was observed that FC appeared to be non-seasonal disease as it occurred nearly all over the year with an increase in the rate of infection during seasonal weather changes as in March, May, July and in winter season in November and December. Similarly, Tsai et al. (2000); Rahman et al. (2004) admitted the seasonal control on the prevalence of FC. It was observed that the highest prevalence of FC occurred during summer season with percent of $(49.12 \%)$ in contrast to rainy $(26.32 \%)$ and winter (24.56\%) seasons. In addition, all infected cases in chickens were farm housing. Housing system was thought to have an effect on the infection due to overcrowding in intensive system of production and stress. Meanwhile, the most affected ducks were from back yard housing and this may be due to bad management, lack of proper medication and introduction of newly purchased birds and rearing different type of birds (ducks with chickens) in the same place. The infection occurred in 4 layer chickens flocks and 2 breeder flocks and 3 broiler flocks. The higher incidence was in layer flocks may be due to stress of egg production. But in ducks, all affected flocks were broiler. In our survey, age susceptibility in chickens and ducks agreed with Talha et al. (2001); Rahman et al. (2004). Mbuthia (2004) clarified that the susceptible ages were 12 weeks old in chickens and 8 weeks old in ducks. Sukul et al. (2008) mentioned that FC primarily affected ducks less than 8 weeks of age. Mortality rate per week was generally low in both chickens and ducks farms compared to total number of bird per flock. This finding may be due to proper medication and vaccination system. However, the mortality rate 2 backyard duck flocks was higher than that of chicken may be due to low total number of birds, presence of stress, age of diseased birds, poor management and resistant power of the bird breed.

In the present study, gross findings of FC in chickens including congested body, cyanotic comb, cloudy air sacs, congested pneumonic lungs with adhesion, congested and enlarged liver with friable texture and pin point grayish white foci, fibrinous perihepatitis, peritonitis, pericarditis with congested or hemorrhagic coronary fat, congested kidneys, enlarged congested spleen with sometimes fibrinous capsule, congested intestinal serosal blood vessels with sometimes thickened mesentery were in agreement with previous literatures reported by Mbuthia et al. (2001); Arshed et al. (2003); Zhang et al. (2004); Zahoor and Siddique (2006); Mohamed (2009); Srinivasan et al. (2011). Gross examination of affected ducks was similar to those reported by Kwon and Kang (2003); Islam et al. (2003); Medani et al. (2004); Afifi and El-Nesr, (2013) including congested or pale kidneys, congested and enlarged liver with friable texture and pin point grayish white foci. Brain did not show any gross lesions in agreement with Gustafson et al. (1998). Skin of footpad was thickened due to hyperkeratosis and granulomatous dermatitis. Meanwhile, Christensen and Bisgaard (2000) recorded fibrino-necrotic dermatitis in skin of affected ducks. Hock joint was swollen due to deposition of fibrinopurulent exudate inside joints as stated by Glisson et al. (2003).

In the present study, the microscopic examination of different tissues from infected chickens was greatly similar to those reported by Gustafson et al. (1998); Christensen and Bisgaard, (2000); Shivapreased and Droual, (2002); Mbuthia, (2004); Medani et al. (2004); Zhang et al. (2004); Mohamed, (2009); Mbuthia et al. (2011); Afifi and El-Nesr, (2013); Panna et al. (2015). Multiple granulomata were also detected by Shivapreased and Droual, (2002) in tissues of broiler chicken experimentally infected with $P$. gallinarunm. However in our microscopic 
findings, focal granuloma was demonstrated in chicken only in lungs. On the other hand, microscopic examination of different tissues of ducks revealed presence of multiple granulomata in trachea, lung, liver, heart, gizzard and skin as mentioned by Afifi and El-Nesr, (2013). Other lesions including coagulative necrosis and degenerative changes (such as fatty changes and vacuolar degeneration) in hepatocytes, diffuse and focal heterophilic infiltrations in the portal areas and hepatic parenchyma, severe depletion of lymphocytes from lymphoid follicles in spleen due to necrosis of lymphocytes and increased reticulocytes congested intestinal blood vessels were also described in ducks as previously reported by Arshed et al. (2003); Kwon and Kang, (2003); Zhang et al. (2004); Afifi and ElNesr, (2013). Cerebral hemispheres of duck brain showed focal gliosis, perivascular lymphocytic cuffing in Virchow-Robin space and congested blood vessels with hemolyzed blood as previously reported by Gustafson et al. (1998); Afifi and El-Nesr, (2013). The hock joint of ducks showed ulceration of epiphyseal cartilage covered with fibrinous and heterophilic exudates as previously mentioned by Arshed et al. (2003).

Because of difficulty of PCR application on all samples, IHC was used to localize antigen of $P$. multocida in different organs from chickens and ducks. Our IHC results revealed positive brown immunolabelling for $P$. multocida capsular type A antigen in lung, liver, s pleen and kidney. The IHC score in chickens was $(+3)$ in liver and $(+2)$ in lungs. Liver was generally the best organ to diagnose FC in chicken according to Tahir et al. (2003); Samuel et al. (2007).

In chicken lungs, positive brown immunolabelling (score +2$)$ for $P$. multocida capsular type A antigen was detected in interstitial tissue and inside blood in blood vessels and in inter alveolar capillaries. In the same way, Mbuthia et al. (2001) detected $P$. multocida in chicken lung tissues by using fluorescent rRNA in situ hybridization single, in pairs, as microcolonies and as massive colonies within air capillaries (septa and lumen), parabronchial septa and blood vessels (wall and lumen). In general, the presence of the positive immunolabelling for $P$. multocida inside circulated blood indicated acute septicemic infection and its presence inside the affected tissues indicated the virulence of $P$. multocida (Strugnell et al., 2011). IHC staining in ducks showed positive brown immunolabelling for $P$. multocida capsular type A antigen inside all examined organs with higher IHC scores than those recorded in chickens. Afifi and El-Nesr, (2013) stained $P$. multocida antigen only inside hepatocytes of duck. Strugnell et al. (2011) reported a positive reaction for $P$. multocida in corvid lung by IHC extracellularly or within the foamy cytoplasm of macrophages and in necrotic foci. Generally, the histopathological lesions in the infected ducks were more severe than those detected in the infected chickens. Therefore, the IHC positive reactions were more intense and more widely distributed in infected ducks than in the infected chickens. In an experimental study, Mbuthia et al. (2008) reported more significantly severe clinical signs of FC in 8week-old ducks than in 12-week-old chickens. It may be attributed to the lowered resistance of young aged ducks or due to the ability of chickens to clear $P$. multocida organisms from their oropharynx and cloacae faster than the ducks as mentioned by Mbuthia et al. (2008).

\section{REFERENCES}

Adhikary, S.; Bisgaard, M.; Foster, G.; Kiessling, N.; Fahlén, A.R.; Olsen, J.E. and Christensen, $H$. (2013): Comparative study of PCR methods to detect Pasteurella multocida. Berl Munch Tierarztl Wochenschr J. 126(9-10): 415-22.

Afifi, S.I. and El-Nesr, K.A. (2013): Bacteriological, Pathological and Immunohistochemical Studies on Pasteurella Spp. Isolated from Ducks in Beni Suef Governorate. Egypt. J. Comp. Path \& Clinic Path. 26 (1): 28- 48.

Arshed, M.J.; Siddique, M. and Sajjad-ur-Rahman. (2003): Preliminary Studies on Fowl Cholera in Layers. Pak. j. life soc. sci. 1(1): 34-36.

Bancroft, S. and Stevens, R. (1990): Theory and practice of histological techniques.3rd Ed. Churchill Livingstone, New York.

Blanchong, J.A.; Samuel, M.D.; Goldberg, D.R.; Shadduck, D.J. and Creekmore,L. H. (2006): Wetlands environmental conditions associated with the risk of avian cholera outbreaks and the abundance of Pasteurella mlultocida. Journal of Wildlife Management 70:54-60.

Brooks, G.F.; Butel, J.S. and Morse, S.A. (2002): Jawetz, Melnick and Adelberg's Medical Microbiology. 22th edn. MacGraw Hill, New Delhi, India, pp 197-202.

Charitha Devi, M.; Kiran Kumar, J. and Harshavardan Reddy, P. (2012): Isolation and Partial characterization of Pasteurella multocida from poultry farms around Tirupati. J. Microbiol. Biotech. Res., 2 (3):393-395.

Christensen, H. and Bisgaard, M. (2003): The genus Pasteurella. In The prokaryotes: an evolving electronic resource for the microbiological community, Ver. 3.13. (M. Dworkin \& C. Lyons, eds). Springer-Verlag, New York, 1062-1090.

Christensen, J.P. and Bisgaard, M. (2000): Fowl cholera. Rev. Sci. Tech. Off. Int. Epiz.19, 626637.

Deena, J. and Adriana, L.Y. (2005): Gram stain: Gram-negative rod, microbes. American Society for Microbiology. http/www. microbelibrary.org. 
Glisson, J.R.; Hofacre, C.L. and Christensen, J.P. (2003): Fowl cholera. In Diseases of Poultry, pp. 658-676.

Glisson, J.R.; Hofacre, C.L. and Christensen, J.P. (2008): Fowl cholera. In Y. M. Saif, \& A. M. Fadly (Eds.), Diseases of poultry. (12 ed., pp. 739-758).

Gustafson, C.R.; Cooper, G.L.; Charlton, B.R. and Bickford, A.A. (1998): Pasteurella multocida infection involving cranial air spaces in White Leghorn chickens. Avian Dis., 42: 413-417.

Islam, M.A.; Samad, M.A.; Rahman, M.B. and Kabir, S.M.L. (2003): Clinicopathological changes of experimentally induced Fowl cholera in Jinding ducks. Bangladesh Journal of Veterinary Medicine 1(1): 9-13.

Jonas, M.; Morishita, T.Y.; Angrick, E.J. and Jahja, J. (2001): Characterization of nine Pasteurella multocida isolates from avian cholera outbreaks in Indonesia. Avian diseases, 45:3442.

Kapetanov, M.; Kapetanov, R.; Suvajdzic, L. and Velhner, M. (2000): Cholera caused by Pasteurella in breeder flocks. Zivinarstvo, 35: 211-213.

Kehrenberg, C.; Schulze-Tanzil, G.; Martel, J.L.; Chaslus-Dancla, E. and Schwarz, S. (2001): Antimicrobial resistance in Pasteurella and Mannheimia: epidemiology and genetic basis. Vet Res, 32 (3-4), 323339.

Khamesipour, F.; Momtaz, H. and Mamoreh, M.A. (2014): Occurrence of virulence factors and antimicrobial resistance in Pasteurella multocida strains isolated from slaughter cattle in Iran. Frontiers in Microbiology, Infectious Diseases, 5(536):1-9.

Kwon, Y.K. and Kang, M.I. (2003): Outbreak of fowl cholera in Baikal Teals in Korea. Avian diseases 47:1491-1495.

Lichtensteiger, C.A.; Steenbergen, S.M.; Lee, R.M.; Polson, D.D. and Vimr, E.R. (1996): Direct PCR Analysis for Toxigenic Pasteurella multocida. Clinical microbiology j., 34(12):3035-3039.

Mbuthia, P.G.; Christensen, H.; Boye, M.; Petersen, K.M.D.; Bisgaard, M.; Nyaga, P.N. and Olsen, J.E. (2001): Specific detection of pasteurella multocida in chickens with fowl cholera and in pig lung tissues using fluorescent rRNA in situ hybridization. Clinical microbiology J., 39(7): 2627-2633.

Mbuthia, P.G.; Njagi, L.W.; Nyaga, P.N.; Bebora, L.C.; Minga, U.; Christensen, J.P. and Olsen, J.E. (2011): Time-course investigation of infection with a low virulent Pasteurella multocida strain in normal and immunesuppressed 12-week-old free-range chickens. Avian Pathology, 40 (6): 629-637.

Mbuthia, P.G. (2004): "Pasteurella Multocida in Indigenous Chickens and Ducks in Kenya: - A study of carrier status, susceptibility, molecular diagnosis and Pathogenesis, University of Nairobi. PhD Thesis.

Mbuthia, P.G.; Njagil, L.W.; Nyagal, P.N.; Beboral, L.C.; Minga, U.; Kamundia, J. and Olsen, J.E. (2008): Pasteurella multocida in scavenging family chickens and ducks: carrier status, age susceptibility and transmission between species. Avian Pathology J. 37(1), 51-57.

Medani, G.G.; Desouki, A. and Sobhy, N.M. (2004): Bacteriological, Mycological and Histopathological Studies On Zoo Birds Suffering from Respiratory Manifestations Benha Vet. Med. J., 15(2): 172-187.

Mohamed, M.A.; Mohamed, M.W.; Ahmed, I.A.; Ibrahim, A.A. and Ahmed, M.S. (2012): Pasteurella multocida in backyard chickens in Upper Egypt: incidence with polymerase chain reaction analysis for capsule type,virulen ce in chicken embryos and antimicrobial resistance. Veterinaria Italiana J., Vol. 48(1): 77-86.

Mohamed, S.M. (2009): Hematological biochemical immunological and pathological studies on pasteurellosis in chicken. Egypt. J. Comp. Path. and Clinic. Path. Vol. (22) No. (2): 195209.

Naowarat, C. (2007): Eosin-Methylene Blue. American Society for Microbiology. http ://www.microbelibrary. org.

OIE (2008): Fowl cholera. O.I.E Terrestrial Manual 2. 3. 9:524-530.

OIE (2012): OIE Terrestrial Manual. Chapter 2.4.12. Haemorrhagic septicaemia

Ozbey, G. and Muz, A. (2006): Isolation of aerobic bacteria from the lungs of chickens showing respiratory disorders and confirmation of Pasteurella multocida by polymerase chain reaction (PCR). Vet. arhiv 76, 217-225.

Panna, S.N.; Nazir, N.H.; Rahman, M.B.; Ahamed, S.; Saroare, M.G.; Chakma, S.; Kamal, T. and Majumder, U.H. (2015): Isolation and molecular detection of Pasteurella multocida Type A from naturally infected chickens, and their histopathological evaluation in artificially infected chickens in Bangladesh. J. Adv. Vet. Anim. Res., 2(3): 338-345.

Petersen, K.D.; Christensen, J.P.; Permin, A. and Bisgaard, M. (2001): Virulence of Pasteurella multocida subsp. multocida isolated from outbreaks of fowl cholera in wild birds for domestic poultry and game birds. Avian Pathology 30:27-31.

Petersen, S.K. and Foged, N.T. (1989): Cloning and Expression of the Pasteurella multocida Toxin Gene, toxA, in Escherichia coli. Infection and immunity J. 57: 3907-3913.

Rahman, M.A.; Samad, M.A.; Rahman, M.B. and Kabir, S.M.L. (2004): Bacterio-pathological studies on Salmonellosis, Colibacillosis and 
Pasteurellosis in Natural and Experimental Infections in Chickens. Bangl. J. Vet. Med. 2(1): 01-08.

Saad Eldin, W.F. and Reda, L.M. (2016): Epidemiological prevalence of Pasteurella multocida in ducks. Japanese Journal of Veterinary Research, 64(Supplement 2): S251S255.

Samuel, M.D.; Botzler, R.G. and Wobeser, G.A. (2007): Avian Cholera. Infectious diseases of wild birds. N.J. Thomas, D.B. Hunter and C.T. Atkinson, (Eds), Blackwell Publishing, Ames, Iowa, Pp. 239- 269.

Samuel, M.D.; Shadduck, D.J.; Goldberg, D.R.; Wilson, M.A.; Joly, D.O. and Lehr, M.A. (2003): Characterization of Pasteurella multocida isolates from wetland ecosystems during 1996 to 1999. Journal o/Wildlife Diseases 39:798-807.

Sellyei, B.; Varga, Z.; Ivanics, E. and Magyar, T. (2008): Characterisation and comparison of avian Pasteurella multocida strains by conventional and ERIC-PCR assays. Acta Veterinaria Hungarica, 56: 429-440.

Shivaprasad, H.L. and Droual, R. (2002): Pathology of an atypical strain of Pasteurella gallinarum infection in chickens. Avian Pathology, 31(4): 399-406.

Simensen, E. and Olson, D. (2001): Relationship of increased fowl cholera outbreaks in turkeys with high environmental temperatures. Avian Dis., 45: 461-466.

Srinivasan, P.; Gopalakrishnamurthy, T.R.; Mohan, B. and Saravanan, S. (2011): Occurrence of sub acute fowl cholera in a broiler flock. Tamilnadu J. Veterinary and Animal Sciences 7 (1): 45-47.

Strugnell, B.; Dagleish, M.P.; Bayne, C.W.; Browne, M.; Ainsworth, H.; Nicholas, R.A.J.; Wood, A. and Hodgson, J.C. (2011): Investigations into an outbreak of corvid respiratory disease associated with Pasteurella multocida. Avian pathology 40(03): 329-336.

Sukul, M.; Khan, M.S.R.; Rahman, M.T. and Begum, $K$. (2008): Immunogenicity of capsular extract prepared from a local duck isolate of pasteurella multocida. Bangl. J. Vet. Med. 6 (1): 19-22.

Tahir, B.; Durrani, F.R.; Farooq, M.; Durrani, Z.; Zamin, S.; Khan, M.A. and Riaz, A. (2003): prevalence of fowl cholera (Pasteurella multocida) in commercial broiler breeder flocks maintained in Abbottabad and Mansehra. Animal and veterinary advances $\mathrm{j}$. 2(8): 444-447.

Takahashi, S.; Sato, H.; Yamada, T.; Takenouchi, T.; Sawada, T.; Nakano, K. and Saito, H. (1996): Outbreaks of fowl cholera in Muscovy ducks on a farm in Aomori prefecture. J. Vet. Med. Sci. 58: 269272.

Talha, A.F.S.M.; Hossain, M.M.; Chowdhury, E.H.; Bari, A.S.M.; Islam, M.R. and Das, P.M. (2001): Poultry diseases occurring in Mymansingh district of Bangladesh. Bangladesh veterinarian 18: 20-23.

Townsend, K.M.; Boyce, J.D.; Chung, J.Y.; Frost, A.J. and Adler, B. (2001): Genetic organization of Pasteurella multocida cap loci and development of a multiplex capsular PCR typing system. J Clin Microbiol, 39, 924-929.

Tsai, H.J. and You, W.B. (2000): Occurrence of fowl cholera in poultry flocks in Taiwan. J. of Chinese society of veterinary science 26:147154.

Wilkie, I.W.; Grimes, S.E.; O'Boyle, D. and Frost, A.J. (2000): The virulence and protective efficacy for chickens of Pasteurella multocida administered by different routes. Veterinary Microbiology 72:57-68.

Wilkie, I.W.; Harper, M.; Boyce, J.D. and Adler, B. (2012): Pasteurella multocida: Diseases and Pathogenesis. Current Topics in Microbiology and Immunology, 361:1-22.

Wilson, $K$. (2001): Preparation of genomic DNA from bacteria. In Current protocols in molecular biology, Vol. 1 (F.M. Ausubel, R. Bernt, R.E. Kingston, D.D. Moore, S.J. Seidman, J.A. Smith, K. Srahul, eds). Wiley, New York, 241242.

Woo, Y.K and Kim, J.H. (2006): Fowl cholera outbreak in domestic poultry, The J. of Microbiology, Vol. 44, No. 3:344-353.

Zahoor, R.M.A. and Siddique, M. (2006): Characteristics of $P$. multocida recovered from avian sources. Pakistan Veterinary Journal, 26: 41-43.

Zhang, P.; Fegan, N.; Fraser, I.; Duffy, P.; Bowles, R.E.; Gordon, A.; Ketterer, P.J.; Shinwari. W. and Blackall, P.J. (2004): Molecular epidemiology of two fowl cholera outbreaks on a free-range chicken layer farm. J. Vet Diagn. Invest 16:458-460. 


\section{دراسة باثواوجية وامينو هيستوكيميائية على الباستريللا مالتوسيدا من نوع المحفظة (أ) فى انسجة الدجاج والبط المصاب بكوليرا الطيور \\ سمر غالمى ، ولاء عوضين ، احمد السواق}

Email: walaafekriawadin@yahoo.com Assiut University web-site: www.aun.edu.eg

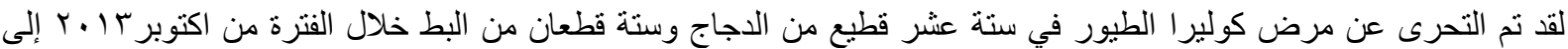

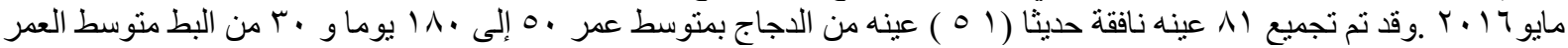

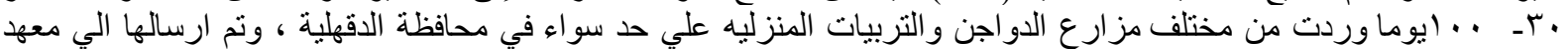

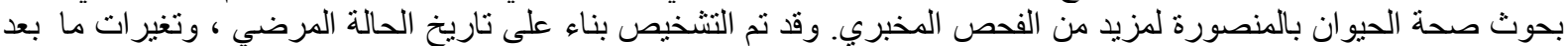

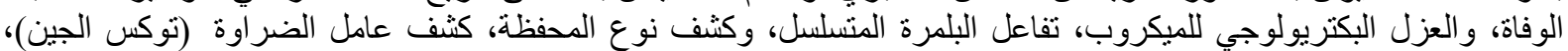

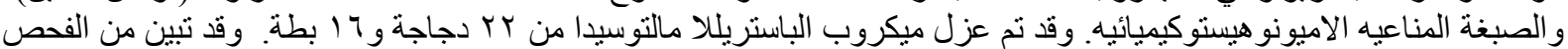

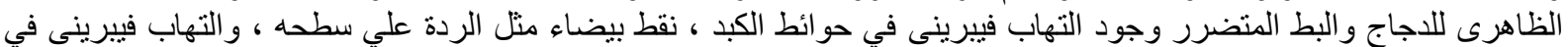

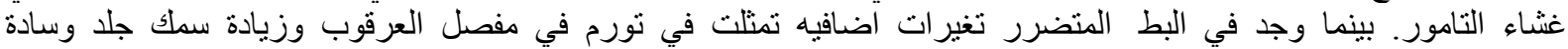

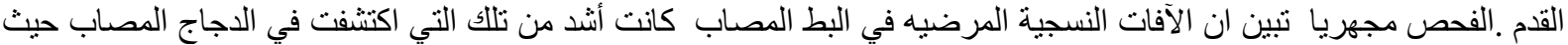

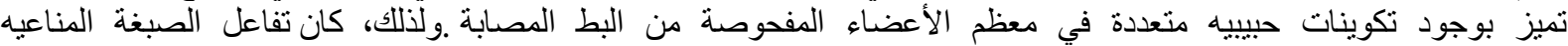

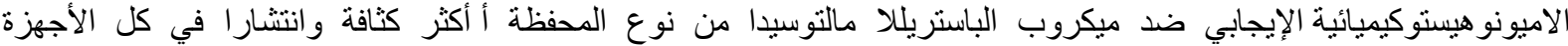

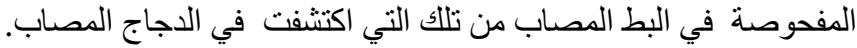

